Article

\title{
Developing invasive weed, social spider, shuffled frog leaping, biogeography-based, and harmony search optimization algorithms for the early prediction of residential building's cooling load simulation
}

\author{
Hossein Moayedi ${ }^{1,2}$, Amir Mosavi ${ }^{3,4}$, \\ 1 Institute of Research and Development, Duy Tan University, Da Nang, 550000, Viet Nam; \\ hosseinmoayedi@duytan.edu.vn \\ 2 Faculty of Civil Engineering, Duy Tan University, Da Nang 550000, Vietnam. \\ 3 School of Economics and Business, Norwegian University of Life Sciences, 1430 Ås, Norway, \\ a.mosavi@ieee.org \\ 4 John von Neumann Faculty of Informatics, Obuda University, 1034 Budapest, Hungary
}

\begin{abstract}
Regarding the high efficiency of metaheuristic techniques in energy performance analysis, this paper scrutinizes and compares five novel optimizers, namely biogeographybased optimization (BBO), invasive weed optimization (IWO), social spider algorithm (SOSA), shuffled frog leaping algorithm (SFLA), and harmony search algorithm (HSA) for the early prediction of cooling load in residential buildings. The algorithms are coupled with a multi-layer perceptron (MLP) to adjust the neural parameters that connect the CL with the influential factors. The complexity of the models is optimized by means of a trial-and-error effort, and it was shown that the BBO and IWO need more crowded spaces for fulfilling the optimization. The results revealed that the internal parameters (i.e., biases and weights) suggested by the BBO generate the most reliable MLP for both analyzing and generalizing the CL pattern (with nearly 93 and 92\% correlations, respectively). Followed by this, the IWO emerged as the second powerful optimizer with mean absolute errors of 1.8632 and 1.9110 in the training and testing phases. Therefore, the BBO-MLP and IWO-MLP can be reliably used for accurate analysis of the CL in future projects.

Keywords: Energy performance; Cooling load prediction; Neural network, Metaheuristic optimization.
\end{abstract}

\section{Introduction}

Providing convenient air condition in energy-efficient buildings is fulfilled by a so-called system "heating, ventilating, and air conditioning (HVAC)" [1]]. Up to now, various methodologies have been employed for optimal modification of these systems [ $\underline{2}, \underline{3}]$. This is while a number of obstructs like high dimensions of the problem as well non-linearity. Mathematical methods, for instance, in spite of acceptable efficiency in finding theoretically optimal solutions, being time-consuming is an appreciable disadvantage for them [4]. These issues have driven scholars to use inverse modeling techniques instead of forwarding approaches []ㅡ. Artificial intelligence (AI) is well known as intelligence techniques explored by machines. It is not involving consciousness and emotionality unlike the natural intelligence displayed by animals and humans [-9-9]. A number of artificial intelligencebased examples are studied such as in the subjects of sustainability [10-12], water [13-18] 
and groundwater supply chains $[\underline{19}, \underline{20}]$, quantifying climatic contributions [21-24], natural gas consumption [25-32], pan evaporation [33-36] and soil and landslide analysis studies [37-39], geographic information system-based studies [40-44], building and structural design analysis [ $\underline{45-51]}$, measurement techniques [52-56], structural material (e.g., steel and concrete) behaviors [57-63], image classification and processing [64-70], computer vision

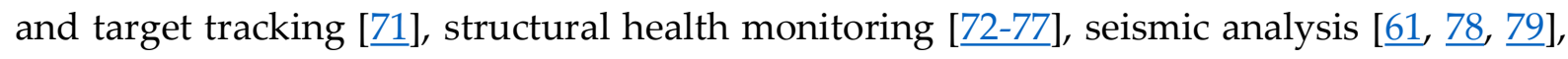
optimizing energy systems [으-86], and environmental concerns [ㅁ-94]. The AI implemented in many novel engineering complex solutions. For instance, decision making -based solutions that rely on the advantages of AI [95-98]. A neural network is distinguished as a series of network-based algorithms that analysis and connect input and output data layer(s) in the similar way that human brain operates [99-105]. Machine learning techniques have shown high accuracy in analyzing the energy performance of buildings [106]. Popular notions like artificial neural network (ANN) [107], as well as support vector machines (SVM) [108] and adaptive neuro-fuzzy inference system (ANFIS) [109], have presented successful predictions of heating load (HL) and cooling load (CL) [110-113]. Furthermore, metaheuristic schemes have emerged as potent analyzers for energy-related problems [ 114 , 115]. Ghahramani, et al. [116] used a metaheuristic technique for optimizing the HVAC system through finding and controlling optimal setpoints at the building level. A self-tuning component was also applied to modify hyperparameters. The results showed that utilizing the proposed model results in around 32\% HVAC energy saving. Ikeda and Ooka [4] employed several well-known optimizers like cuckoo search (CS) and particle swarm optimization (PSO) for optimizing operating schedules of three energy systems including a battery, thermal energy storage, and an air-source heat pump. They found that the proposed methods are far more time-effective than dynamic programming. Fong, et al. [117] used evolutionary programming for optimizing the HVAC system. It was concluded that the proposed reset scheme has a saving potential of nearly $7 \%$ and is more economical than regular operational settings. Likewise, Jitkongchuen and Pacharawongsakda [118] hired a grey wolf optimization (GWO) for modeling the HL and CL of buildings with the residential application.

These algorithms have also shown high capability in optimizing the performance of wellknown predictors. More clearly, most of the typical predictors like ANNs, SVM, and ANFIS encounter problems in the case of high-dimensional problems or might fall into traps like local minima in complex modeling $[\underline{119}, \underline{120}]$. Utilizing optimizers helps proper adjustment of hyperparameters of these models. In studies by Moayedi, et al. [121] and Le, et al. [122], for example, the efficiency of GWO and PSO metaheuristic algorithms for optimizing the ANN is investigated. The optimization robustness of imperialist competition algorithm (ICA) and genetic algorithms (GA) was compared by Tien Bui, et al. [123]. They concluded that both algorithms can effectively reduce the prediction error for both HL (around 18 and $23 \%$, respectively by GA and ICA) and CL (around 21 and 25\%) parameters. The ICA-based ensemble was also introduced as the superior model. The social behavior of the elephant was applied to the same problem by Moayedi, et al. [124] and it was found that the proposed algorithm outperforms those that are based on the lifestyle of ant and Harris hawk. Similarly, Zhou, et al. [125] established a comparison between the artificial bee colony and PSO. Considering the high applicability of metaheuristic algorithms in the field of CL (or) 
HL simulation, this study conducts a comparison between five novel metaheuristic techniques of biogeography-based optimization, invasive weed optimization, social spider algorithm, shuffled frog leaping algorithm, and harmony search algorithm for optimal prediction of cooling load in residential buildings. The results are evaluated by several accuracy criteria to demonstrate the capability of the models in analyzing and predicting the CL pattern. Also, a score-based ranking system is applied to detect the most capable optimizer.

\section{Methodology}

As explained above, this paper studies the optimization of the ANN (for cooling load simulation) by using various optimization techniques. To fulfill this purpose, an MLP neural network is trained by five metaheuristic techniques of BBO, IWO, SOSA, SFLA, and HAS. During this process, the main role of these algorithms is finding the most proper computational parameters of the MLP (i.e., the weights and biases) to surmount the existing drawbacks. A brief description of the named algorithms is presented in this section, and in order to shorten the paper, related references are mentioned for finding more details and mathematical relationships. Biogeography-based optimization (BBO) is a capable search method developed by [126] in 2008, that works based on geographical distributions. This algorithm has been previously used by scholars like Moayedi, et al. [127] to train ANNs for spatial analysis of geotechnical hazards. The solutions of the BBO are represented by habits and the goodness of each of those is measured by a habitat suitability index. This algorithm comprises two steps of migration and mutation during those, the candidate solution is modified to achieve a more fitted response. Also, a mutation process is considered to make the algorithm resistant against local minima.

Mehrabian and Lucas [128] introduced the invasive weed optimization (IWO) as a natureinspired optimizer. As the name implies, the aim of the algorithm is finding the most suitable place for plants (weeds) to grow and reproduce. The IWO is based on five steps, namely (a) initialization, (b) reproduction, (c) spatial dispersal, (d) competitive exclusion, and (e) stopping criteria evaluation. After the reproduction, some seeds are settled near the family and they are combined with the weeds to create the next generation. James and Li [129] designed the social spider algorithm (SOSA) by imitating the way that social spiders seeks food. The agents are social spiders that move within a multidimensional space which is considered their web in this algorithm. The candidate solutions are represented by the positions of the spiders which are highly in touch. Therefore, the spider's positions and the corresponding goodness values are two important ingredients of the SOSA. The optimization information (e.g., fitness values) are recorded in the individuals' memory. In this technique, the intensity of vibrations is indicative of the solution fitness. The shuffled frog leaping algorithm (SFLA) is another popular search technique that is suggested by Eusuff and Lansey [130] in 2003. The SFLA presents a combination of the PSO and Memetic algorithm. As two advantages, simplicity and high convergence speed have made it a broadly-used method. The relations in this algorithm are frogs. These individuals are grouped in so-called units "memeplexes". The fitness of the frogs is the basis of classifying them. After setting in descending order, the best-fitted ones leap as the first member of the 
memeplexes, and then second-fitted frogs are next members and so on. The positions of the frogs get updated to implement the optimization.

The harmony search algorithm (HSA) is introduced by Geem, et al. [131] in 2001. Scholars like have previously used the HSA for optimizing the ANN $[\underline{132}, \underline{133}]$. This algorithm draws on the player's action that intends to improvise the instrument's pitches to achieve a better harmony. A memory called harmony memory is first initialized and then new harmonies are improvised and updated for finding the best responses. This process is carried out by defining two parameters of pitch adjusting rate and harmony memory considering rate. As merit, the HSA (similar to the GA algorithm) possesses a genetic pool to store the solutions. More details, especially mathematical descriptions of the mentioned algorithms can be

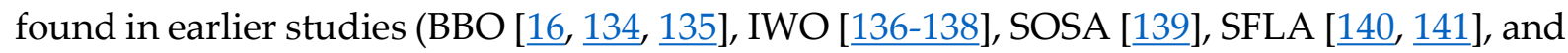
HSA [142-144]).

\section{Data and statistical analysis}

By implementing a vast computer simulation, Tsanas and Xifara [145] provided the dataset used in this study. They employed Ecotect software [146] to acquire information of the cooling load as well as the heating load of a residential building. In this process, the effect of eight environmental factors (glazing area (GA), relative compactness (RC), wall area (WA), surface area (SA), glazing area distribution (GAD), overall height $(\mathrm{OH})$, roof area (RA), and orientation (OR)) of the proposed buildings are taken into consideration.

There are 12 buildings which bring four orientations, four GAs $(0,10,25$ and $40 \%$ of the floor area), and five distribution scenarios. Altogether, 768 cases are analyzed. Figure 1 depicts the distribution of the obtained CLs versus each influential factor. Table 1 is also presented to detail the statistical characteristics of the variables. Out of the provided data, $80 \%$ and 20\% (i.e., 614 and 154 samples) are randomly specified to the training and testing operations, respectively. Famously, the use of the first group is to discover the relationship between the target (i.e., CL) and corresponding independent factors. While the generalizability of the detected CL pattern is assessed by means of the second group.

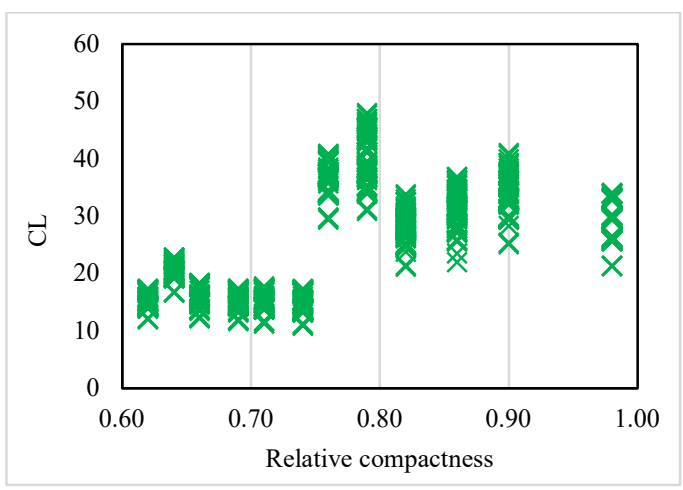

(a)

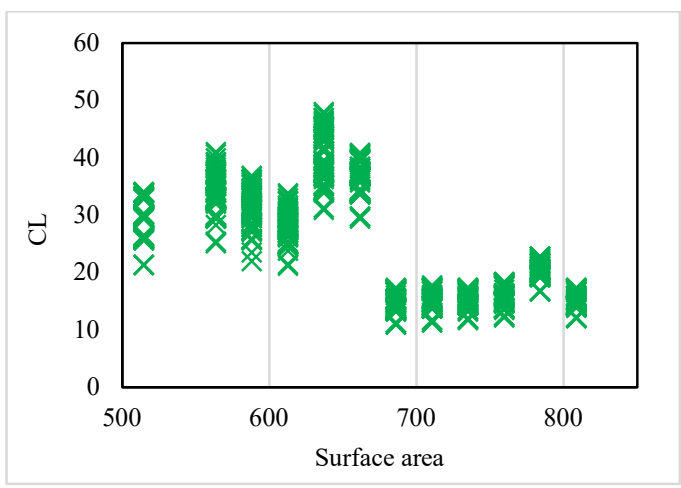

(b) 


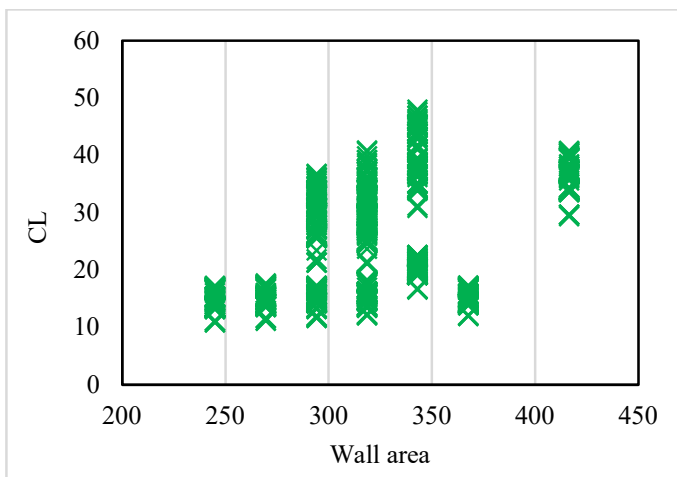

(c)

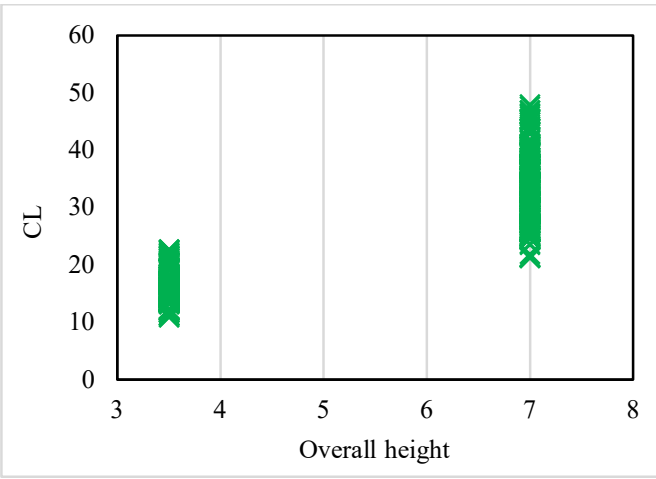

(e)

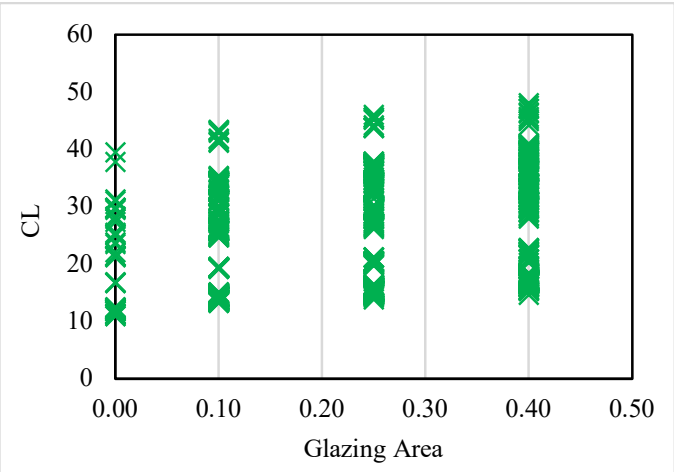

(g)

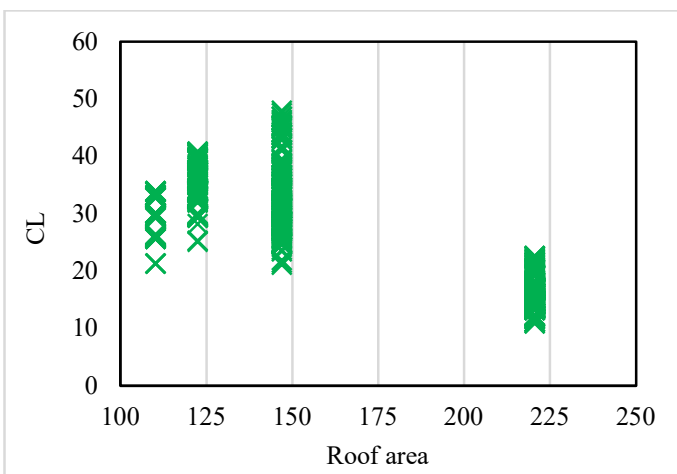

(d)

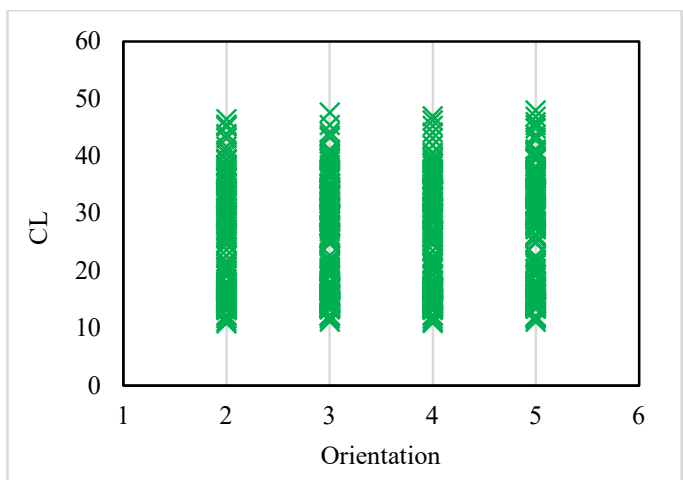

(f)

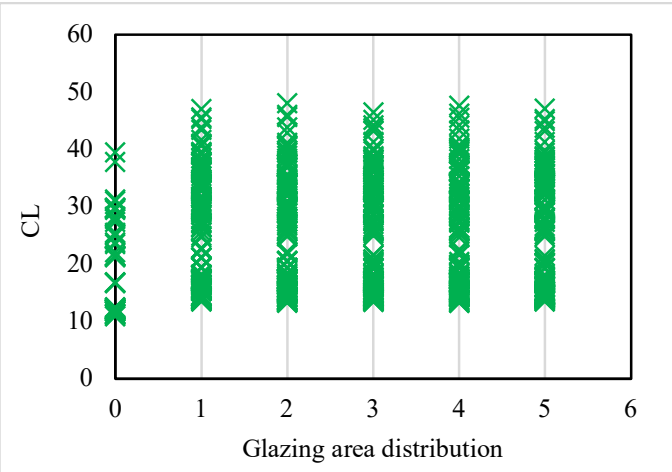

(h)

Figure 1: The obtained CL values vs. influential factors.

Table 1: Statistical analysis implemented for descrbing the ued datset.

\begin{tabular}{cccccccccc}
\hline Index & CL & GA & RC & WA & SA & GAD & OH & RA & OR \\
Mean & 24.59 & 0.23 & 0.76 & 318.5 & 671.71 & 2.81 & 5.25 & 176.6 & 3.5 \\
Standard Error & 0.34 & 0 & 0 & 1.57 & 3.18 & 0.06 & 0.06 & 1.63 & 0.04 \\
Sample Variance & 90.5 & 0.02 & 0.01 & 1903.27 & 7759.16 & 2.41 & 3.07 & 2039.96 & 1.25 \\
Minimum & 10.9 & 0 & 0.62 & 245 & 514.5 & 0 & 3.5 & 110.25 & 2 \\
Maximum & 48.03 & 0.4 & 0.98 & 416.5 & 808.5 & 5 & 7 & 220.5 & 5 \\
\hline
\end{tabular}




\section{Results and discussion}

This work investigates and compares the capability of five novel optimizations of neural computing (BBO-MLP, IWO-MLP, SOSA-MLP, SFLA-MLP, and HSA-MLP) applied to the problem of cooling load prediction. After creating the purposed hybrids, they are fed by both training and testing data to evaluate their learning and generalizing efficiencies, respectively. This work is carried out by means of three accuracy criteria including a correlation measure, namely coefficient of determination $\left(\mathrm{R}^{2}\right)$, as well as mean absolute error (MAE) and root mean square error (RMSE) error measures. These indices are formulated as follows:

$$
\begin{aligned}
& R^{2}=1-\frac{\sum_{i=1}^{Q}\left(C L_{i_{\text {predicted }}}-C L_{i_{\text {observed }}}\right)^{2}}{\sum_{i=1}^{Q}\left(C L_{i_{\text {obseved }}}-\overline{C L}_{\text {observed }}\right)^{2}} \\
& M A E=\frac{1}{Q} \sum_{i=1}^{Q}\left|C L_{i_{\text {obened }}}-C L_{i_{\text {pratcod }}}\right| \\
& R M S E=\sqrt{\frac{1}{Q} \sum_{i=1}^{Q}\left[\left(C L_{i_{\text {obsered }}}-C L_{i_{\text {predicted }}}\right)\right]^{2}}
\end{aligned}
$$

where $Q$ is the number of involved data, and the measured and forecasted CLs are shown by $C L_{i}$ observed and $C L_{i \text { predicted, }}$ respectively. Also, the average of the observed CLs is symbolized by $\overline{C L}_{\text {observed. }}$

\subsection{Coupling the MLP with optimization schemes}

Before developing the hybrid models, the MLP needs to be optimized concerning the number of neurons in the middle layer (NHN). Remarkably, although this network can possess more than three layers (two or more hidden layers), it has been widely shown that a three-layered MLP is adequate for handling every complex problem. Based on a trial and error process, the MLP distinguished by 6 hidden neurons was found the most proper one among 10 tested structures (NHN varied from 1 to 10). Following this, the general equation of the MLP was given to the BBO, IWO, SOSA, SFLA, and HAS so that the computational weights and biases are supposed to be adjusted.

Also, to ensure about using the most appropriate size of the swarm engaged with the problem (e.g., the number of spiders in the SOSA), nine different complexities of each algorithm (with the populations sizes 10, 25, 50, 75, 100, 200, 300, 400, and 500) are implemented and the records are shown in Table 2. A color intensity system is exert to this table to better illustrate the best responses. In this sense, the lower the obtained OF is, the more intense the assigned color is. As is seen, the lowest OFs $(2.5497,2.6586,3.3916,3.3598$, and 2.9010, respectively for the BBO-MLP, IWO-MLP, SOSA-MLP, SFLA-MLP, and HSAMLP) are obtained for the population sizes of 400,400, 100, 10, and 200. Figure 2 depicts the RMSE values (i.e., convergence curves) obtained for these elite structures for observing the optimization behavior of them. 
Table 2: The results of exerted sensitivity analysis based on the RMSE measure.

\begin{tabular}{cccccc}
\hline Population size & BBO & IWO & SOSA & SFLA & HSA \\
\hline 10 & 2.7830 & 3.0975 & 3.6000 & 3.3598 & 3.2623 \\
\hline 25 & 2.6583 & 3.1192 & 3.8355 & 3.4345 & 3.0683 \\
\hline 50 & 2.7492 & 2.8415 & 3.7523 & 3.3967 & 2.9928 \\
\hline 75 & 2.7008 & 2.8921 & 3.6785 & 3.3849 & 2.9956 \\
\hline 100 & 2.6474 & 2.8358 & 3.3916 & 3.4582 & 2.9676 \\
\hline 200 & 2.7357 & 2.7450 & 3.6002 & 3.6002 & 2.9010 \\
\hline 300 & 2.7455 & 2.7374 & 3.5755 & 3.6551 & 2.9063 \\
\hline 400 & 2.5497 & 2.6586 & 3.4228 & 3.9754 & 2.9200 \\
\hline 500 & 2.6722 & 2.7235 & 3.6151 & 3.9322 & 2.9074 \\
\hline
\end{tabular}

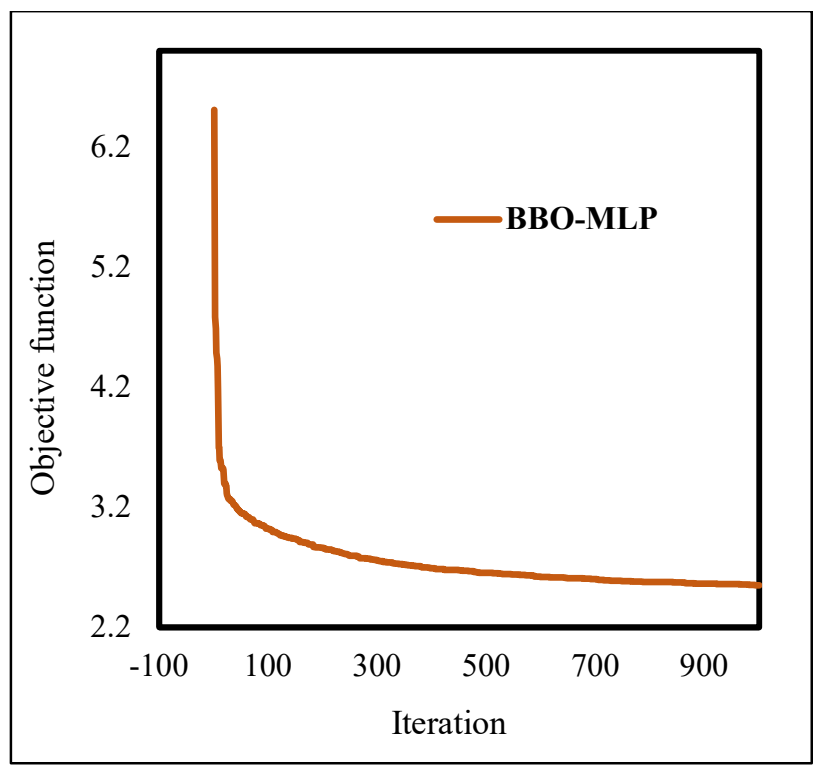

(a)

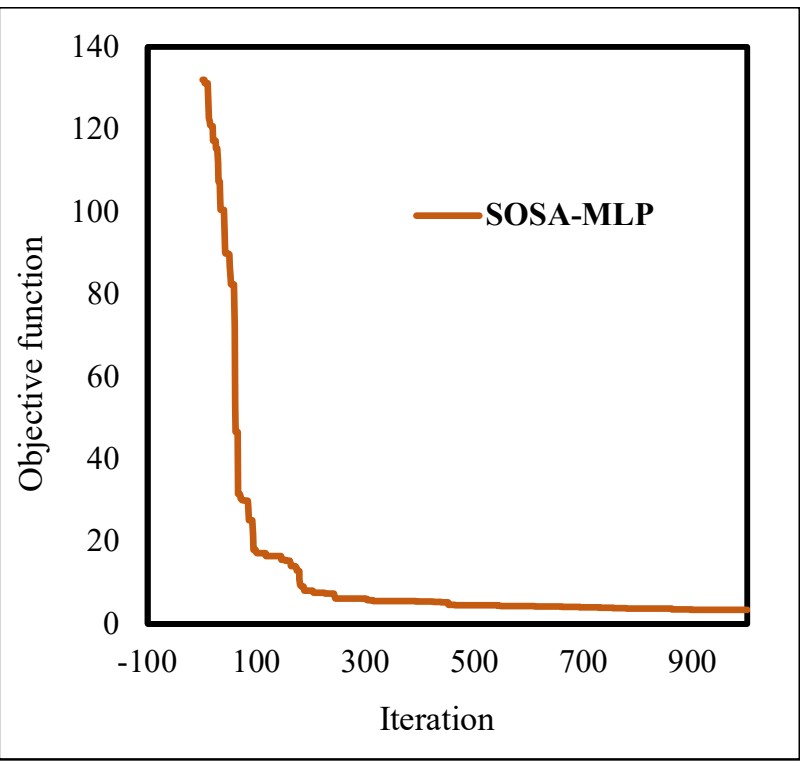

(c)

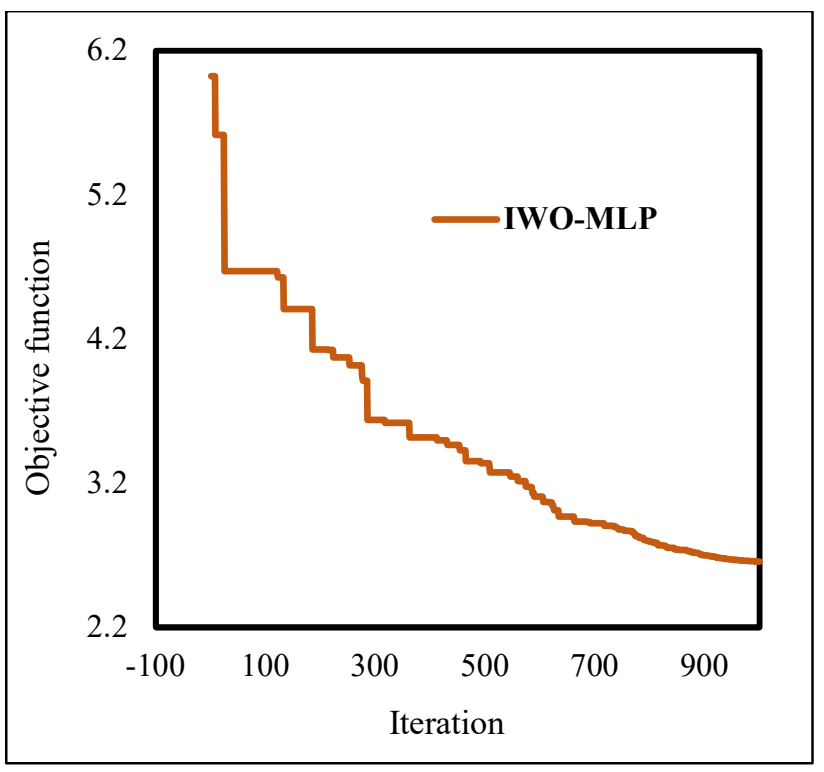

(b)

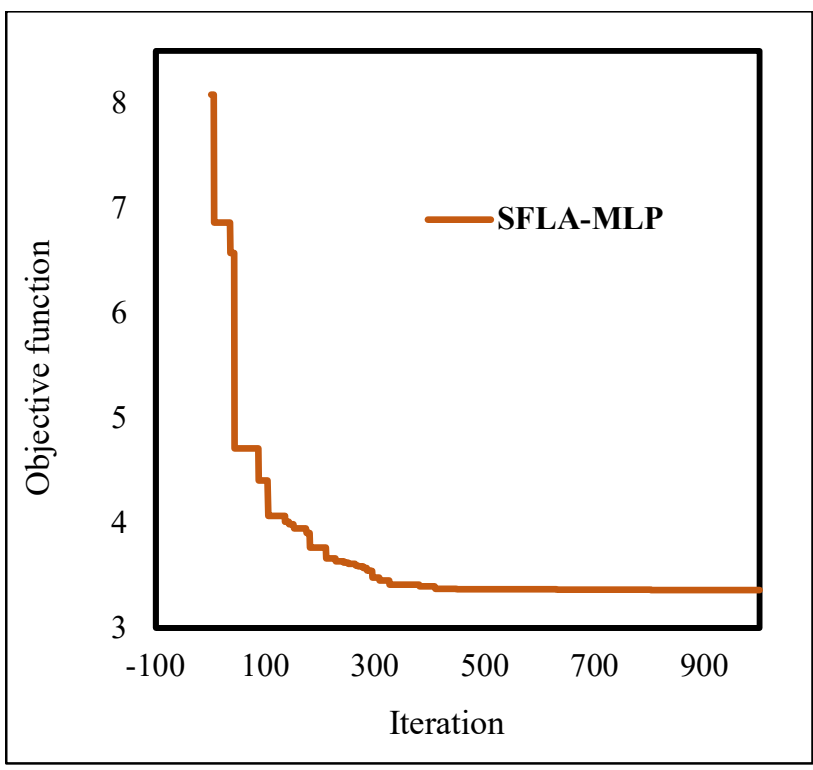

(d) 


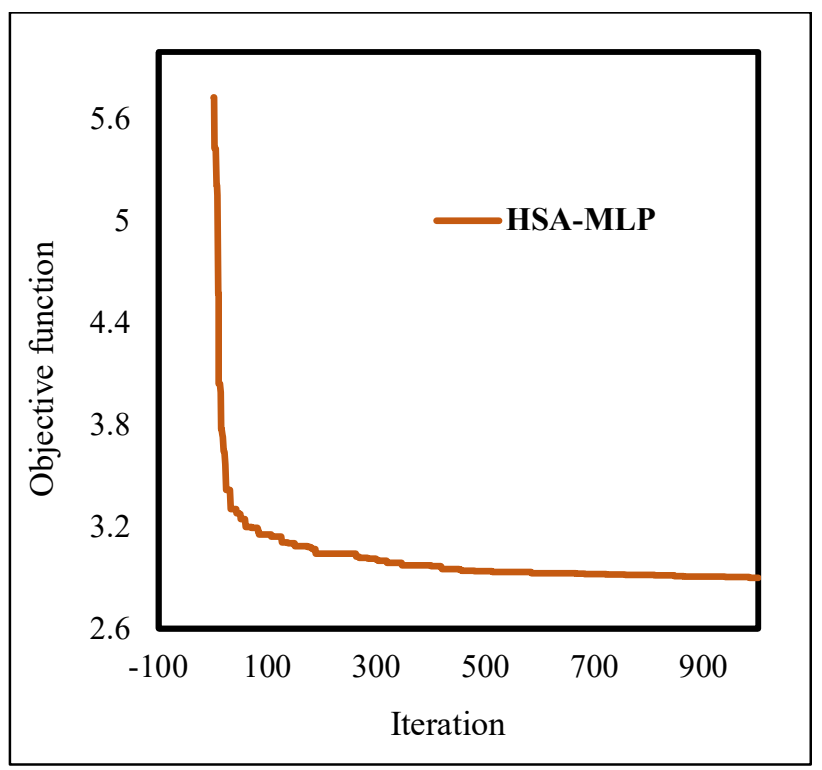

(e)

Figure 2: An illustration of the error reduction procedure extracted from the elite swarm sizes.

Moreover, Figure 3 shows the computation times required for implementing the models with taken population sizes. As explained before, the best populations sizes for the $\mathrm{BBO}$, IWO, SOSA, SFLA were 400, 400, 100, 10, and 200, which took around 7378, 5408, 1311, 330, and 2685 seconds to optimize the MLP.

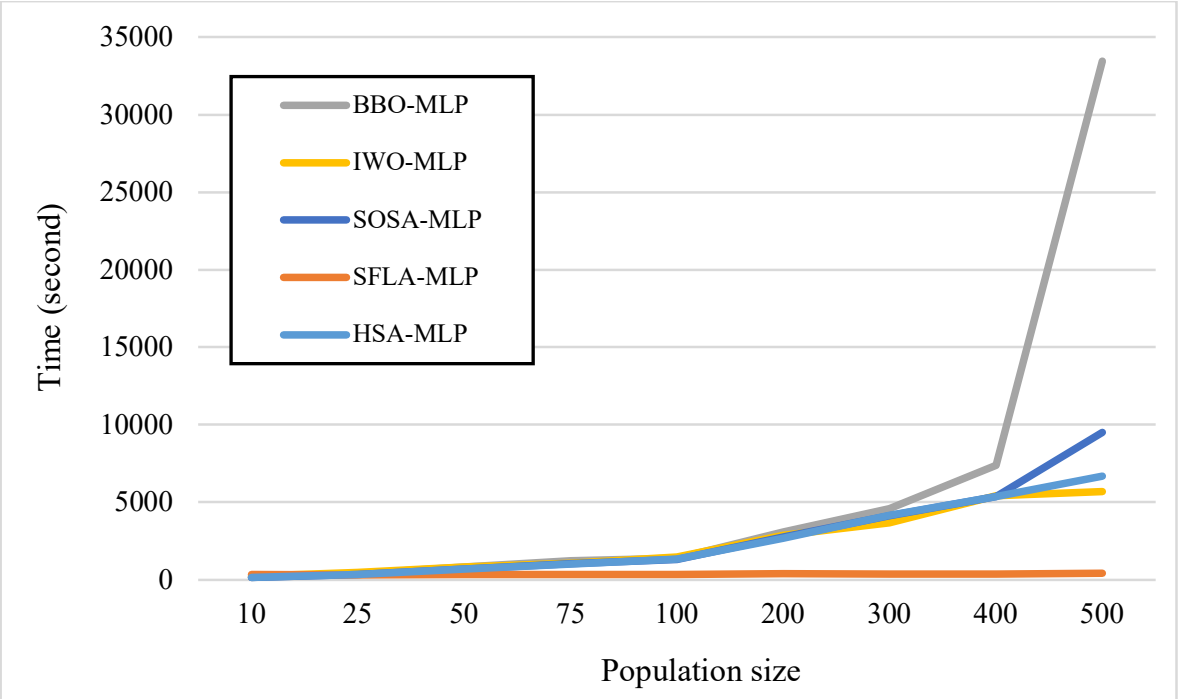

Figure 3: The optimization time taken by the proposed hybrid ensembles.

\section{2 predictive model's reliability assessment}

The results of the training phase are evaluated by comparing the target CLs with predicted values. The regression charts are presented in Figure 4. As mentioned earlier, the $\mathrm{R}^{2}$ reports the correlation where 1 is ideal and vice versa. As is seen, the calculated $\mathrm{R}^{2} \mathrm{~s}$ indicate around $93,92,88,88$, and $91 \%$ agreement between the expected and predicted CLs, respectively for 
the BBO-MLP, IWO-MLP, SOSA-MLP, SFLA-MLP, and HSA-MLP ensembles. The obtained RMSEs $(2.5497,2.6586,3.3916,3.3598$, and 2.9010) also represent a reasonable amount of error in this phase. This claim can be supported by the MAEs of 1.8124, 1.8632, 2.6511, 2.4154, and 1.9256. All these results indicate that the used metaheuristic algorithms can properly analyze the association of the CL to the influential factors by adjusting the MLP's computational parameters.

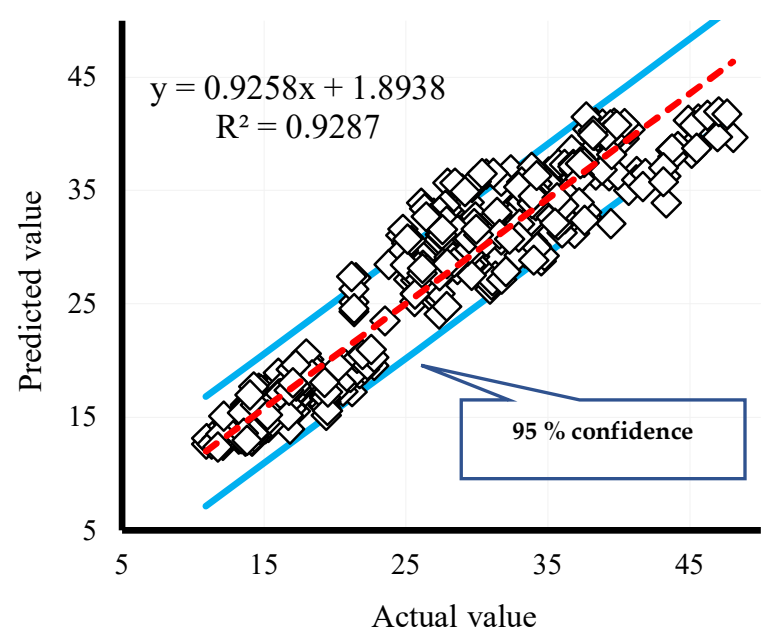

(a)

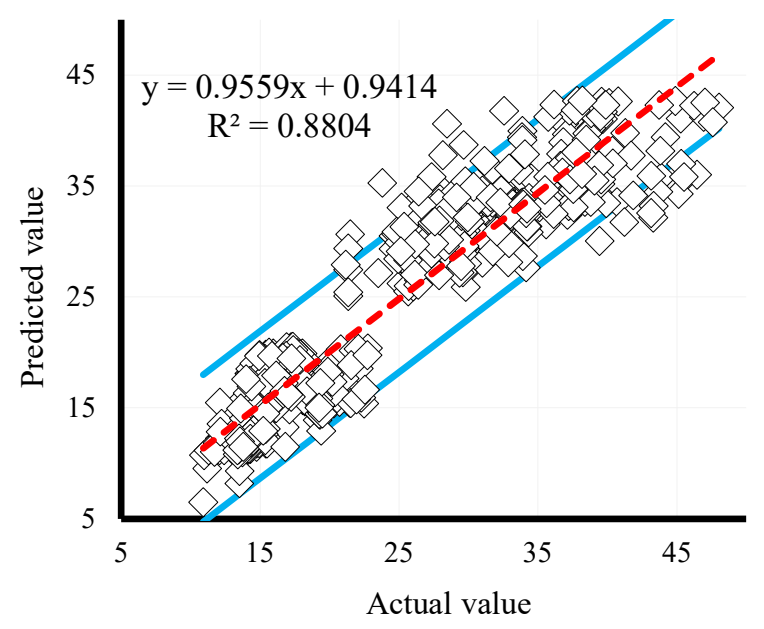

(c)

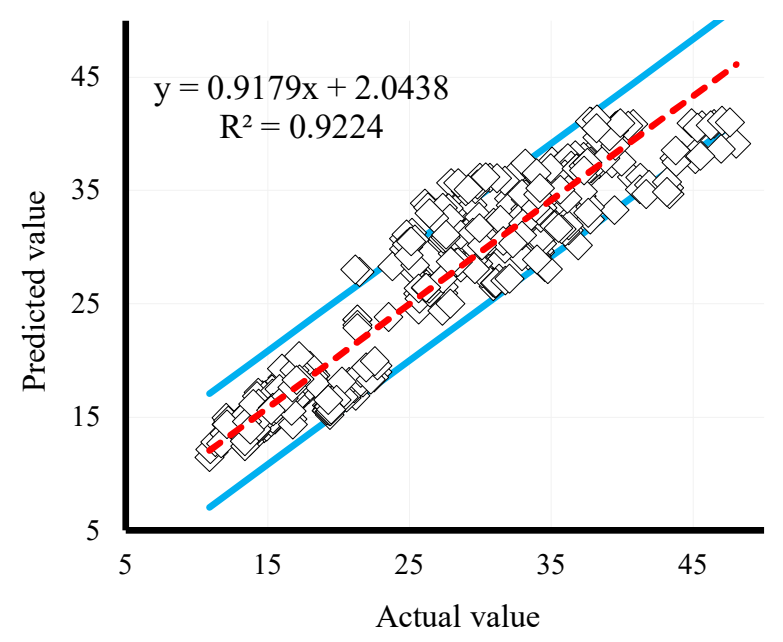

(b)

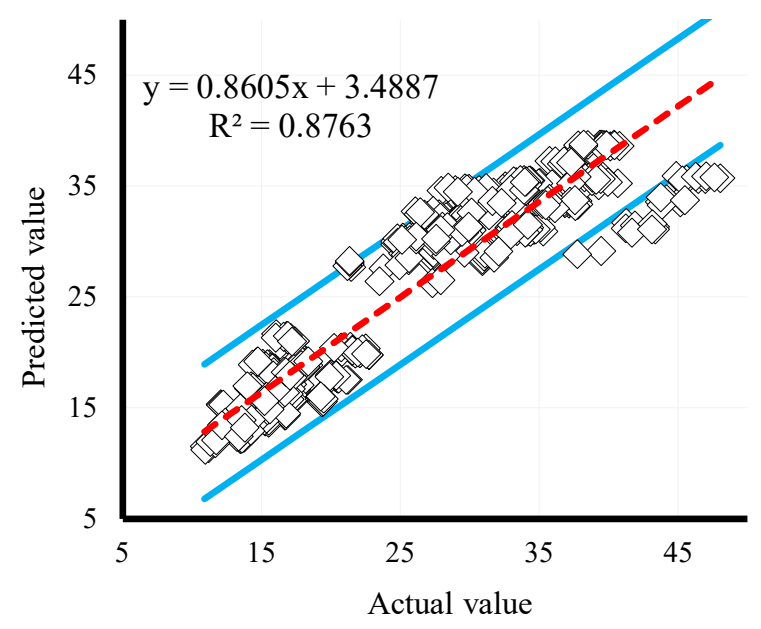

(d) 


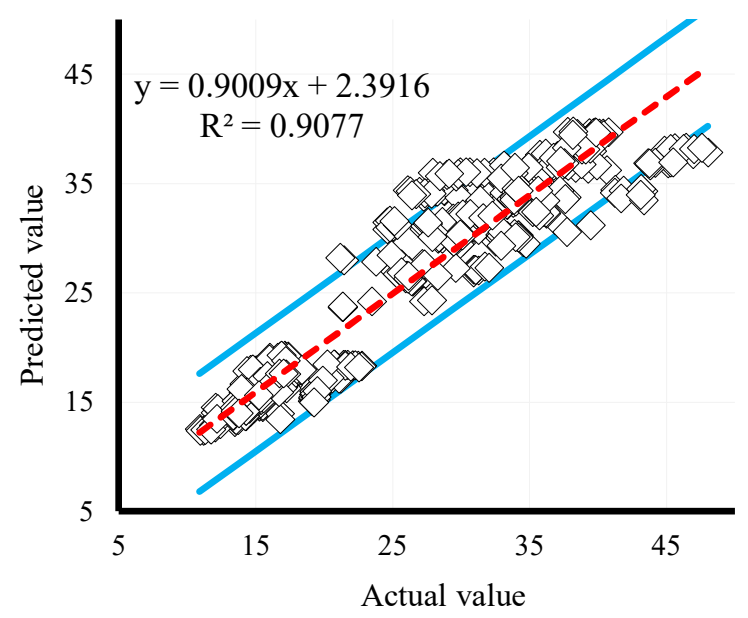

(c)

Figure 4: The regression between the target CLs and those predicted by the (a) BBO-MLP, (b) IWO-MLP, (c) SOSA-MLP, (d) SFLA-MLP, (e) HSA-MLP in the training phase.

The models are then fed by data set aside for testing. Each model applied the established CL pattern to testing data to predict for unseen conditions. The results are shown in Figure 5 that compares the target and predicted testing CLs. According to this figure, all five models can successfully predict the CL pattern.

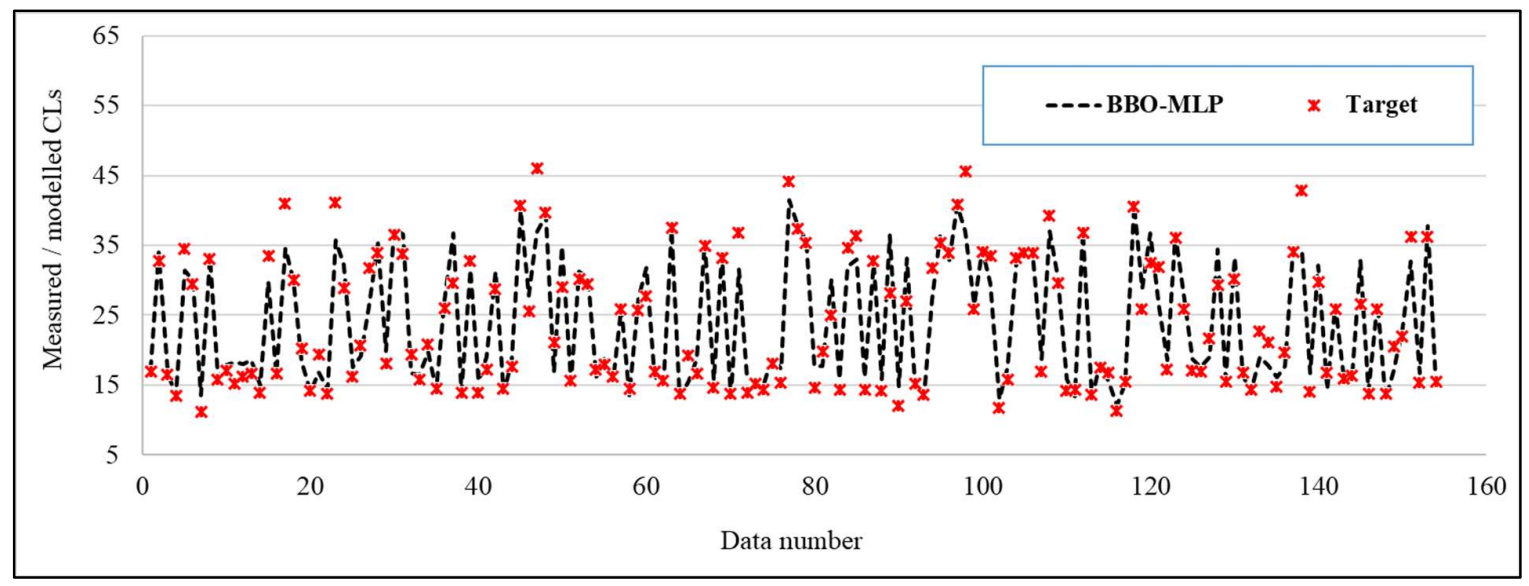

(a)

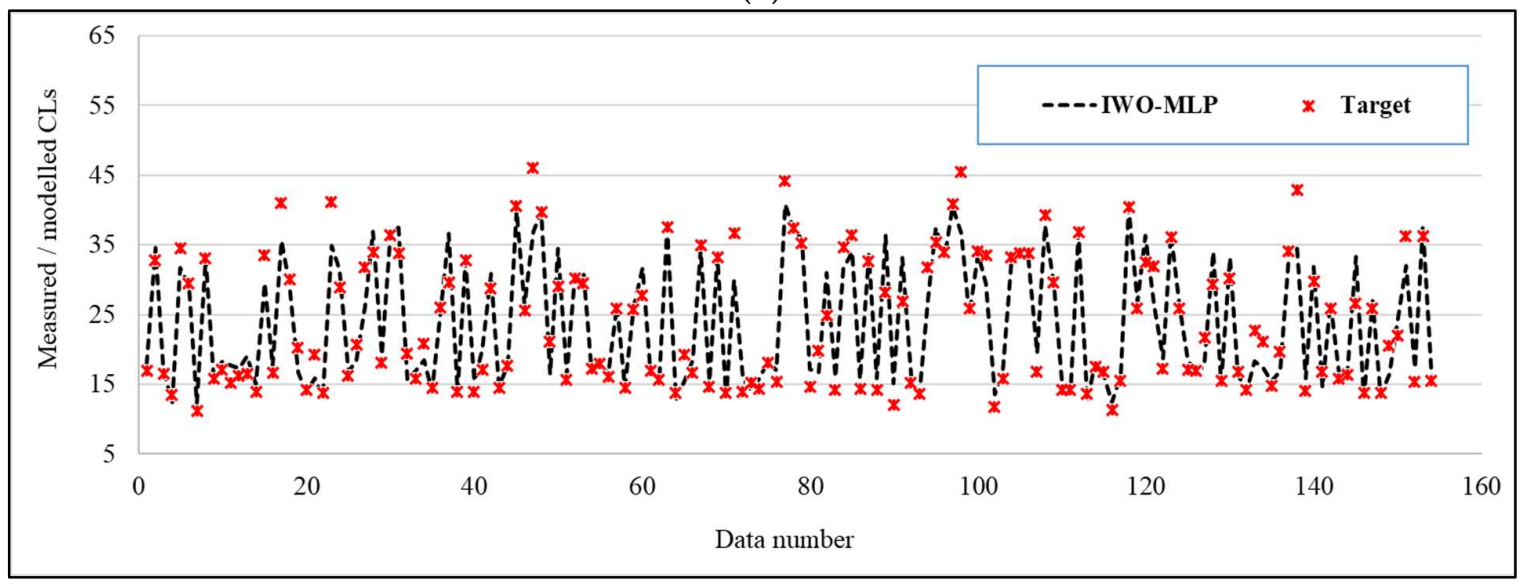

(b) 


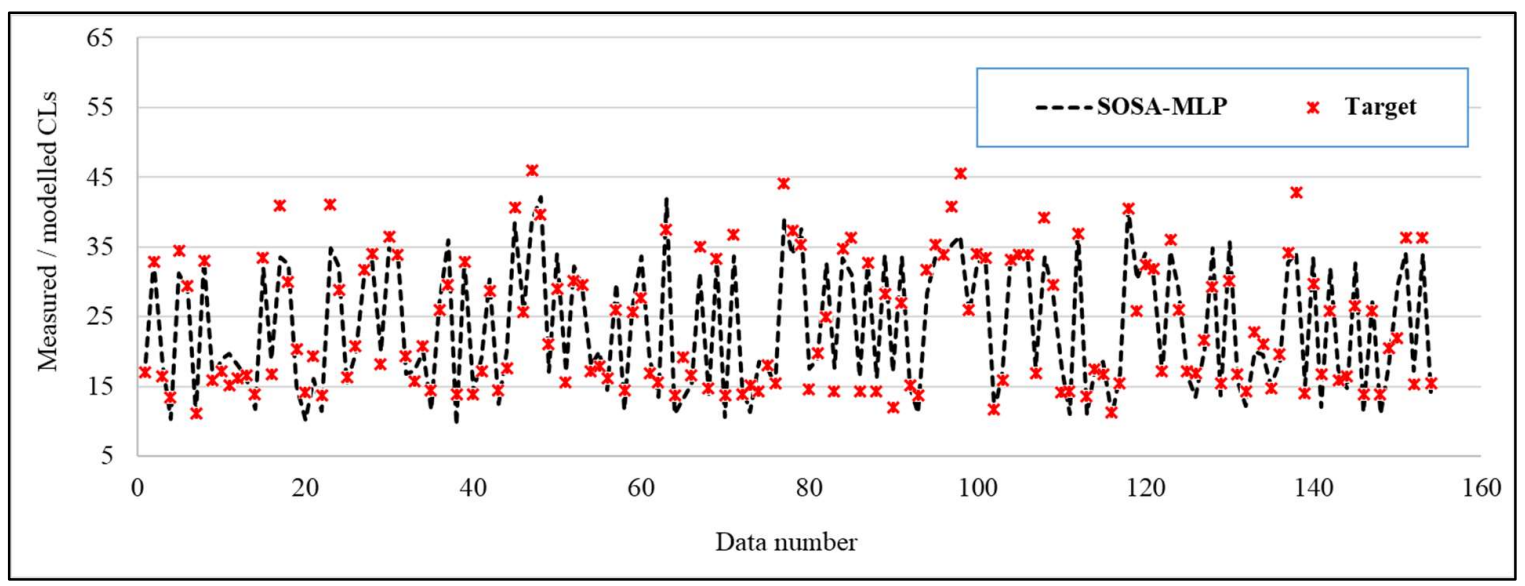

(c)

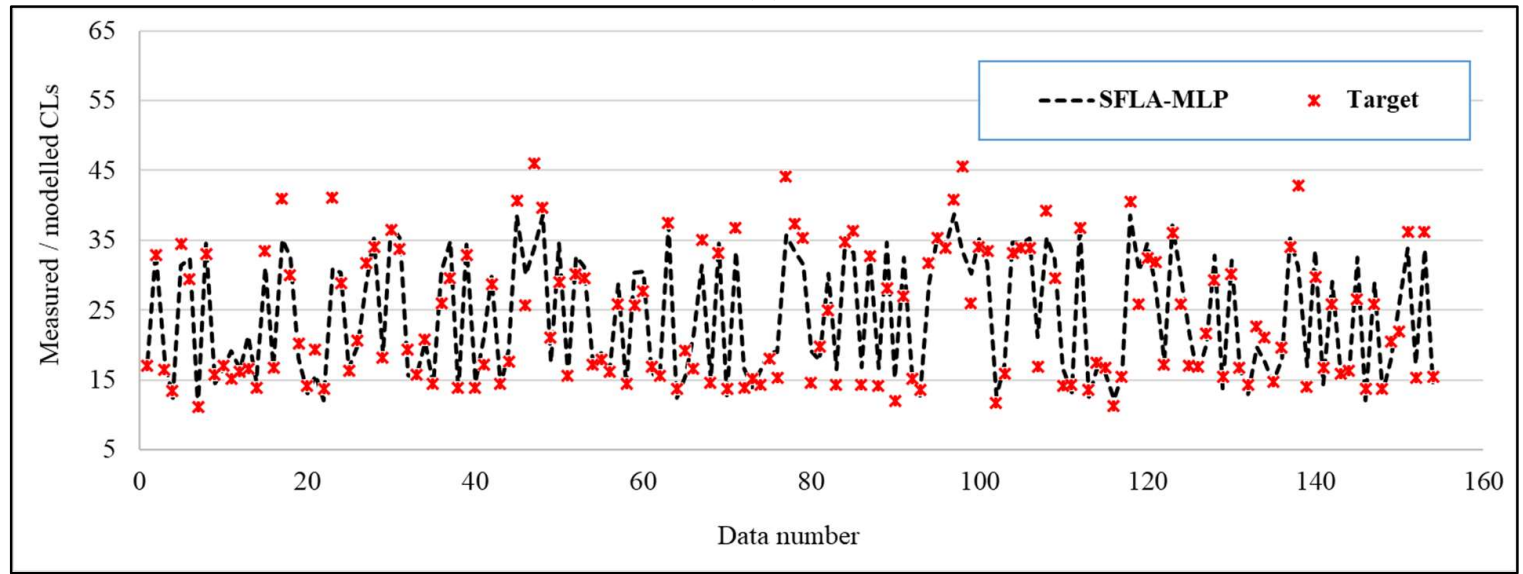

(d)

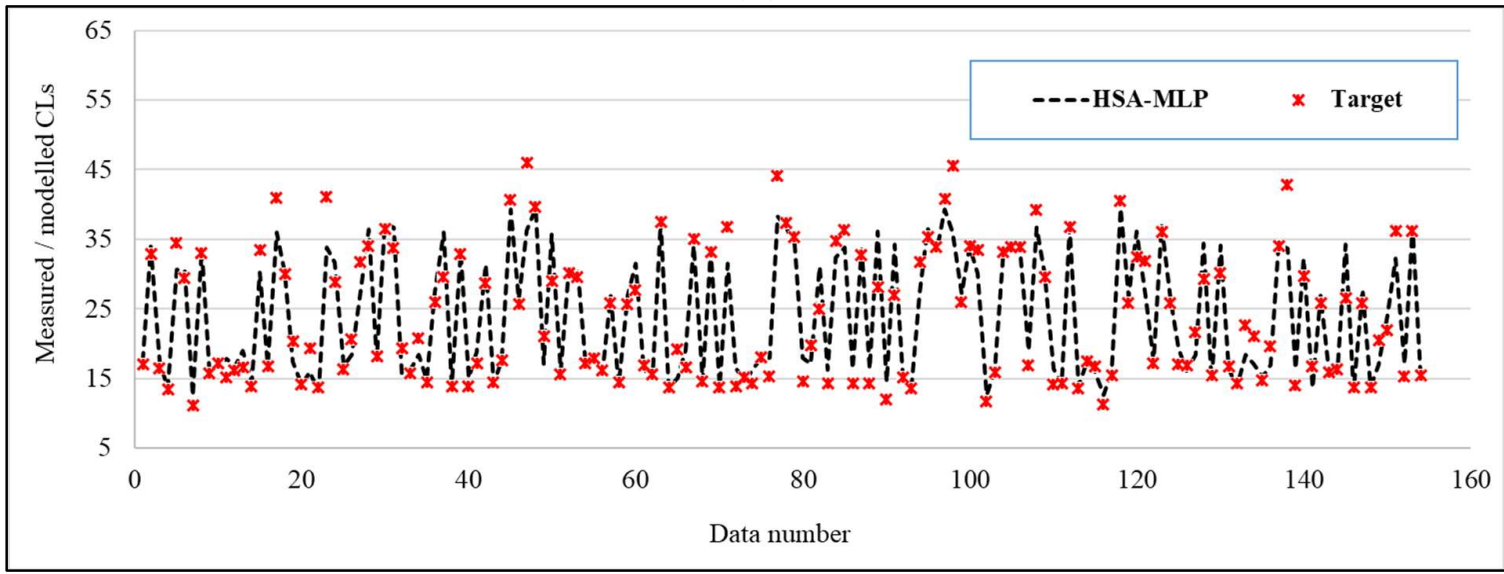

(e)

Figure 5: The testing result for (a) BBO-MLP, (b) IWO-MLP, (c) SOSA-MLP, (d) SFLAMLP, (e) HSA-MLP.

In this phase, the RMSEs are calculated 2.7016, 2.7634, 3.1663, 2.2325, and 2.8536 which, as well as the MAEs of $1.8845,1.9110,2.4575,2.3731$, and 1.9381, represent an acceptable perdition accuracy for all implemented ensembles. Moreover, the correlations of 0.9162, $0.9123,0.8881,0.8801$, and 0.9064 demonstrate high accommodation between the expected and modeled CLs. 
In addition, five maximum and minimum values of actual CLs are compared with network responses in Table 3. The relative error is calculated by Equation 4:

Relative error $=\left(\frac{S_{i \text { predicted }}-S_{i \text { observed }}}{S_{i \text { observed }}}\right) \times 100$

The table denotes that the minimum values are mostly predicted higher than actual ones, while the maximum values are all underestimated. Moreover, the mean absolute relative errors are calculated for all models that give around 14, 15, 16, 18, and $15 \%$ error for the considered data.

Table 3: Relative errors for five maximum/minimum testing CLs.

\begin{tabular}{|c|c|c|c|c|c|c|c|c|c|c|c|}
\hline & \multirow{2}{*}{$\begin{array}{c}\text { Measured } \\
\text { values }\end{array}$} & \multicolumn{5}{|c|}{ Predicted values } & \multicolumn{5}{|c|}{ Error $(\%)$} \\
\hline & & $\begin{array}{l}\text { BBO- } \\
\text { MLP }\end{array}$ & $\begin{array}{l}\text { IWO- } \\
\text { MLP }\end{array}$ & $\begin{array}{l}\text { SOSA- } \\
\text { MLP }\end{array}$ & $\begin{array}{l}\text { SFLA- } \\
\text { MLP }\end{array}$ & $\begin{array}{l}\text { HSA- } \\
\text { MLP }\end{array}$ & $\begin{array}{l}\text { BBO- } \\
\text { MLP }\end{array}$ & $\begin{array}{l}\text { IWO- } \\
\text { MLP }\end{array}$ & $\begin{array}{l}\text { SOSA- } \\
\text { MLP }\end{array}$ & $\begin{array}{l}\text { SFLA- } \\
\text { MLP }\end{array}$ & $\begin{array}{l}\text { HSA- } \\
\text { MLP }\end{array}$ \\
\hline \multirow{5}{*}{ Minimum } & 11.17 & 13.55 & 12.26 & 11.07 & 11.12 & 12.45 & 21.3 & 9.8 & -0.9 & -0.5 & 11.5 \\
\hline & 11.27 & 12.17 & 12.35 & 10.73 & 12.19 & 12.65 & 8.0 & 9.6 & -4.8 & 8.2 & 12.2 \\
\hline & 11.73 & 12.98 & 13.55 & 11.41 & 12.65 & 12.71 & 10.6 & 15.5 & -2.7 & 7.9 & 8.3 \\
\hline & 12.04 & 14.87 & 15.14 & 17.11 & 15.24 & 14.52 & 23.5 & 25.8 & 42.2 & 26.6 & 20.6 \\
\hline & 13.43 & 13.35 & 12.38 & 10.39 & 12.42 & 13.60 & -0.6 & -7.8 & -22.7 & -7.5 & 1.3 \\
\hline \multirow{5}{*}{ Maximum } & 45.97 & 36.91 & 36.94 & 38.77 & 33.62 & 36.33 & -19.7 & -19.6 & -15.7 & -26.9 & -21.0 \\
\hline & 45.52 & 37.05 & 36.58 & 36.61 & 33.50 & 36.05 & -18.6 & -19.6 & -19.6 & -26.4 & -20.8 \\
\hline & 44.18 & 41.55 & 40.75 & 38.95 & 35.72 & 38.24 & -6.0 & -7.8 & -11.8 & -19.2 & -13.4 \\
\hline & 42.86 & 33.98 & 34.93 & 34.04 & 31.23 & 33.72 & -20.7 & -18.5 & -20.6 & -27.1 & -21.3 \\
\hline & 41.07 & 35.72 & 34.86 & 34.85 & 30.95 & 33.85 & -13.0 & -15.1 & -15.1 & -24.6 & -17.6 \\
\hline \multicolumn{7}{|c|}{ Mean absolute relative error } & 14.2 & 14.9 & 15.6 & 17.5 & 14.8 \\
\hline
\end{tabular}

\subsection{Efficiency evaluation and comparison}

In this section, the employed predictive models are compared to identify the most efficient one. The resulted values of all three accuracy indices (RMSE, MAE, and $\mathrm{R}^{2}$ ) are presented in Table 4. In Table 5, these values are ranked based on a score-based system. Compared to the other four models, each index receives a score and the overall score (OS) for each phase is calculated by the summation of three partial ones. Referring to the calculated OSs, the BBO trains the MLP more powerfully than other metaheuristic algorithms. After that, the IWO and HAS emerg as the second and third capable trainers, respectively. The same rankings are also observed for the testing phase. To sum up, the BBO-MLP is selected as the most competent predictor in this research, followed by IWO-MLP, HSA-MLP, SFLA-MLP, and SOSA-MLP. 
Table 4: Resulted statistical measures in the CL simulation.

\begin{tabular}{ccccccc}
\hline \multirow{2}{*}{ Models } & \multicolumn{5}{c}{ Network results } \\
\cline { 2 - 7 } & \multicolumn{5}{c}{ Training } & \multicolumn{3}{c}{ Testing } \\
\cline { 2 - 7 } & RMSE & MAE & $\mathbf{R}^{2}$ & RMSE & MAE & $\mathbf{R}^{2}$ \\
\hline BBO-MLP & 2.5497 & 1.8124 & 0.9287 & 2.7016 & 1.8845 & 0.9162 \\
\hline IWO-MLP & 2.6586 & 1.8632 & 0.9224 & 2.7634 & 1.9110 & 0.9123 \\
\hline SOSA-MLP & 3.3916 & 2.6511 & 0.8804 & 3.1663 & 2.4575 & 0.8881 \\
\hline SFLA-MLP & 3.3598 & 2.4154 & 0.8763 & 2.2325 & 2.3731 & 0.8801 \\
\hline HSA-MLP & 2.9010 & 1.9256 & 0.9077 & 2.8536 & 1.9381 & 0.9064 \\
\hline
\end{tabular}

Table 5: The executed ranking system based on RMSE, MAE, and $\mathrm{R}^{2}$.

\begin{tabular}{|c|c|c|c|c|c|c|c|c|c|c|}
\hline \multirow{3}{*}{ Models } & \multicolumn{10}{|c|}{ Scores } \\
\hline & \multicolumn{5}{|c|}{ Training } & \multicolumn{5}{|c|}{ Testing } \\
\hline & $\begin{array}{c}\text { RMS } \\
\text { E }\end{array}$ & $\begin{array}{c}\text { MA } \\
\text { E }\end{array}$ & $\mathbf{R}^{2}$ & $\begin{array}{l}\text { Overal } \\
\text { l score }\end{array}$ & $\begin{array}{c}\text { Ran } \\
\mathbf{k}\end{array}$ & RMSE & $\begin{array}{c}\text { MA } \\
\text { E }\end{array}$ & $\mathbf{R}^{2}$ & $\begin{array}{c}\text { Overall } \\
\text { score }\end{array}$ & Rank \\
\hline BBO-MLP & 5 & 5 & 5 & 15 & 1 & 4 & 5 & 5 & 14 & 1 \\
\hline IWO-MLP & 4 & 4 & 4 & 12 & 2 & 3 & 4 & 4 & 11 & 2 \\
\hline SOSA-MLP & 1 & 1 & 2 & 4 & 5 & 1 & 1 & 2 & 4 & 5 \\
\hline SFLA-MLP & 2 & 2 & 1 & 5 & 4 & 5 & 2 & 1 & 8 & 3 \\
\hline HSA-MLP & 3 & 3 & 3 & 9 & 3 & 2 & 3 & 3 & 8 & 3 \\
\hline
\end{tabular}

\subsection{The SCE-based CL predictive formula}

With this in mind that the BBO featured as the most efficient optimizer among five tested ones, the BBO-based formula for predicting the CL is presented in this section. Equation 5 gives the mentioned formula. It, however, is required to first use Equation 6 to produce the middle parameters Z1, Z2, .., Z6. Notably, the term Tansig (Equation 7) represents the activation function of the hidden neurons.

Specifically speaking, the numbers that can be seen in these two equations are the BBOoptimized internal biases and weights of the MLP. According to Equation 6, the input factors (i.e., GA, RC, WA, SA, GAD, OH, RA, and OR) are multiplied by the corresponding weights, and after adding the bias terms, the resulted value is activated by Tansig. The products released by this process are then given to the output neuron to calculate the overall response.

$C L_{\text {Bво-MLP }}=0.8751 \times A-0.4726 \times B-0.6899 \times C-0.0762 \times D+0.8955 \times E-0.7985 \times F-0.6410$

$$
\left.\left[\begin{array}{l}
Z 1 \\
Z 2 \\
Z 3 \\
Z 4 \\
Z 5 \\
Z 6
\end{array}\right]=\text { Tansig }\left[\left(\begin{array}{cccccccc}
-0.8207 & 0.3913 & -0.5403 & 0.8097 & -0.4120 & 0.5009 & -0.9241 & 0.1370 \\
0.1050 & -0.7612 & 0.6952 & 0.4735 & -1.1318 & 0.1922 & 0.6162 & 0.2683 \\
0.4925 & 0.8053 & 0.4201 & -0.4442 & 0.7216 & 0.4579 & -0.8314 & -0.6173 \\
-0.7768 & -0.2053 & 0.6888 & -0.2552 & -1.1336 & 0.6313 & -0.1481 & 0.4207 \\
-0.7354 & -0.9265 & -0.5899 & -0.0071 & -0.9120 & -0.4349 & 0.2035 & 0.5080 \\
-0.1547 & -0.7562 & 1.0644 & 0.6912 & 0.0166 & -0.8966 & 0.0924 & -0.2201
\end{array}\right]\left[\begin{array}{c}
R C \\
S A \\
W A \\
R A \\
O H \\
O R \\
G A \\
G A D
\end{array}\right]\right)\left[\begin{array}{c}
1.7514 \\
-1.0509 \\
-0.3503 \\
-0.3503 \\
-1.0509 \\
-1.7514
\end{array}\right]\right)
$$




\section{Conclusions}

This paper investigated five capable metaheuristic techniques, namely biogeography-based optimization, invasive weed optimization, social spider algorithm, shuffled frog leaping algorithm, and harmony search algorithm for the early prediction of cooling load in residential buildings. The named algorithms were applied to a neural processor model for adjusting hyperparameters to develop the corresponding ensemble. Optimizing the complexity of the models showed that the best-required population sizes for both BBO-MLP and IWO-MLP are 400, while this value was 100, 10, and 200 for the SOSA-MLP, SFLA-MLP, and HSA-MLP, respectively. Comparing the prediction results showed that the BBO creates the most accurate MLP in both analyzing and predicting the CL pattern. After that, the IWO outperformed the SOSA, SFLA, and HSA in adjusting the MLP parameters. Regarding the outstanding performance of the BBO-MLP, the CL predictive formula of this method was extracted and presented.

Author Contributions: H.M. methodology; software validation, writing-original draft preparation, A.M. writing - review and editing, visualization, supervision, project administration. All authors have read and agreed to the published version of the manuscript.

Funding: This research was not funded

Conflicts of Interest: The authors declare no conflict of interest.

\section{References}

1. McQuiston, F. C.; Parker, J. D., Heating, ventilating, and air conditioning: analysis and design. 1982.

2. Wemhoff, A.; Frank, M., Predictions of energy savings in HVAC systems by lumped models. Energy and Buildings 2010, 42, (10), 1807-1814.

3. Baek, J.; Kim, E.; Park, M. In Adaptive Fuzzy Output Feedback Control for the Nonlinear Heating, Ventilating, and Air Conditioning System, ITC-CSCC: International Technical Conference on Circuits Systems, Computers and Communications, 2008; pp 1477-1480.

4. Ikeda, S.; Ooka, R., Metaheuristic optimization methods for a comprehensive operating schedule of battery, thermal energy storage, and heat source in a building energy system. Applied energy 2015, 151, 192-205.

5. Gao, W.; Alsarraf, J.; Moayedi, H.; Shahsavar, A.; Nguyen, H., Comprehensive preference learning and feature validity for designing energy-efficient residential buildings using machine learning paradigms. Applied Soft Computing 2019, 84, 105748.

6. Chao, L.; Zhang, K.; Li, Z.; Zhu, Y.; Wang, J.; Yu, Z., Geographically weighted regression based methods for merging satellite and gauge precipitation. Journal of Hydrology 2018, 558, 275-289.

7. Li, T.; Xu, M.; Zhu, C.; Yang, R.; Wang, Z.; Guan, Z., A Deep Learning Approach for Multi-Frame In-Loop Filter of HEVC. IEEE Transactions on Image Processing 2019, 28, (11), 5663-5678.

8. $\quad$ Xu, M.; Li, T.; Wang, Z.; Deng, X.; Yang, R.; Guan, Z., Reducing Complexity of HEVC: A Deep Learning Approach. IEEE Transactions on Image Processing 2018, 27, (10), 5044-5059.

9. Zhang, H.; Qiu, Z.; Cao, J.; Abdel-Aty, M.; Xiong, L., Event-Triggered Synchronization for Neutral-Type SemiMarkovian Neural Networks With Partial Mode-Dependent Time-Varying Delays. IEEE Transactions on Neural Networks and Learning Systems 2020, 31, (11), 4437-4450.

10. He, L.; Shao, F.; Ren, L., Sustainability appraisal of desired contaminated groundwater remediation strategies: an information-entropy-based stochastic multi-criteria preference model. Environment, Development and Sustainability 2020, 1-21.

11. Hu, X.; Chong, H.-Y.; Wang, X., Sustainability perceptions of off-site manufacturing stakeholders in Australia. Journal of Cleaner Production 2019, 227, 346-354.

12. Liu, J.; Yi, Y.; Wang, X., Exploring factors influencing construction waste reduction: A structural equation modeling approach. Journal of Cleaner Production 2020, 276, 123185.

13. Chen, H.; Chen, A.; Xu, L.; Xie, H.; Qiao, H.; Lin, Q.; Cai, K., A deep learning CNN architecture applied in smart near-infrared analysis of water pollution for agricultural irrigation resources. Agricultural Water Management 2020, 240, 106303.

14. Li, X.; Zhang, R.; Zhang, X.; Zhu, P.; Yao, T., Silver-Catalyzed Decarboxylative Allylation of Difluoroarylacetic Acids with Allyl Sulfones in Water. Chemistry - An Asian Journal 2020, 15, (7), 1175-1179. 
15. Quan, Q.; Hao, Z.; Xifeng, H.; Jingchun, L., Research on water temperature prediction based on improved support vector regression. Neural Computing and Applications 2020, 1-10.

16. Savsani, V.; Patel, V.; Tawhid, M., Biogeography Based Optimization for Water Pump Switching Problem. In Nature-Inspired Methods for Metaheuristics Optimization, Springer: 2020; pp 183-202.

17. Yang, W.; Zhao, Y.; Wang, D.; Wu, H.; Lin, A.; He, L., Using Principal Components Analysis and IDW Interpolation to Determine Spatial and Temporal Changes of Surface Water Quality of Xin'anjiang River in Huangshan, China. International Journal of Environmental Research and Public Health 2020, 17, (8), 2942.

18. Chen, Y.; Li, J.; Lu, H.; Yan, P., Coupling system dynamics analysis and risk aversion programming for optimizing the mixed noise-driven shale gas-water supply chains. Journal of Cleaner Production 2021, 278, 123209.

19. Cheng, X.; He, L.; Lu, H.; Chen, Y.; Ren, L., Optimal water resources management and system benefit for the Marcellus shale-gas reservoir in Pennsylvania and West Virginia. Journal of Hydrology 2016, 540, 412-422.

20. Lu, H.; Tian, P.; He, L., Evaluating the global potential of aquifer thermal energy storage and determining the potential worldwide hotspots driven by socio-economic, geo-hydrologic and climatic conditions. Renewable and Sustainable Energy Reviews 2019, 112, 788-796.

21. Zhang, K.; Wang, Q.; Chao, L.; Ye, J.; Li, Z.; Yu, Z.; Yang, T.; Ju, Q., Ground observation-based analysis of soil moisture spatiotemporal variability across a humid to semi-humid transitional zone in China. Journal of Hydrology 2019, 574, 903-914.

22. Roy, D. K.; Barzegar, R.; Quilty, J.; Adamowski, J., Using ensembles of adaptive neuro-fuzzy inference system and optimization algorithms to predict reference evapotranspiration in subtropical climatic zones. Journal of Hydrology 2020, 591, (December 2020), 125509.

23. Tian, P.; Lu, H.; Feng, W.; Guan, Y.; Xue, Y., Large decrease in streamflow and sediment load of QinghaiTibetan Plateau driven by future climate change: A case study in Lhasa River Basin. CATENA 2020, 187, 104340.

24. Zhang, K.; Ruben, G. B.; Li, X.; Li, Z.; Yu, Z.; Xia, J.; Dong, Z., A comprehensive assessment framework for quantifying climatic and anthropogenic contributions to streamflow changes: A case study in a typical semi-arid North China basin. Environmental Modelling \& Software 2020, 128, 104704.

25. Liu, E.; Guo, B.; Lv, L.; Qiao, W.; Azimi, M., Numerical simulation and simplified calculation method for heat exchange performance of dry air cooler in natural gas pipeline compressor station. Energy Science \& Engineering 2020, 8, (6), 2256-2270.

26. Liu, E.; Wang, X.; Zhao, W.; Su, Z.; Chen, Q., Analysis and Research on Pipeline Vibration of a Natural Gas Compressor Station and Vibration Reduction Measures. Energy \& Fuels 2020.

27. Peng, S.; Chen, Q.; Zheng, C.; Liu, E., Analysis of particle deposition in a new-type rectifying plate system during shale gas extraction. Energy Science \& Engineering 2020, 8, (3), 702-717.

28. Peng, S.; Zhang, Z.; Liu, E.; Liu, W.; Qiao, W., A new hybrid algorithm model for prediction of internal corrosion rate of multiphase pipeline. Journal of Natural Gas Science and Engineering 2021, 85, 103716.

29. He, L.; Chen, Y.; Zhao, H.; Tian, P.; Xue, Y.; Chen, L., Game-based analysis of energy-water nexus for identifying environmental impacts during Shale gas operations under stochastic input. Science of The Total Environment 2018, 627, 1585-1601.

30. Li, Z.-G.; Cheng, H.; Gu, T.-Y., Research on dynamic relationship between natural gas consumption and economic growth in China. Structural Change and Economic Dynamics 2019, 49, 334-339.

31. Liu, E.; Lv, L.; Yi, Y.; Xie, P., Research on the Steady Operation Optimization Model of Natural Gas Pipeline Considering the Combined Operation of Air Coolers and Compressors. IEEE Access 2019, 7, 83251-83265.

32. Su, Z.; Liu, E.; Xu, Y.; Xie, P.; Shang, C.; Zhu, Q., Flow field and noise characteristics of manifold in natural gas transportation station. Oil \& Gas Science and Technology-Revue d'IFP Energies nouvelles 2019, 74, 70.

33. Zhang, B.; Xu, D.; Liu, Y.; Li, F.; Cai, J.; Du, L., Multi-scale evapotranspiration of summer maize and the controlling meteorological factors in north China. Agricultural and Forest Meteorology 2016, 216, 1-12.

34. Ghaemi, A.; Rezaie-Balf, M.; Adamowski, J.; Kisi, O.; Quilty, J., On the applicability of maximum overlap discrete wavelet transform integrated with MARS and M5 model tree for monthly pan evaporation prediction. Agricultural and Forest Meteorology 2019, 278, 107647.

35. Keshtegar, B.; Heddam, S.; Sebbar, A.; Zhu, S.-P.; Trung, N.-T., SVR-RSM: a hybrid heuristic method for modeling monthly pan evaporation. Environmental Science and Pollution Research 2019, 26, (35), 35807 35826.

36. Kisi, O.; Heddam, S., Evaporation modelling by heuristic regression approaches using only temperature data. Hydrological Sciences Journal 2019, 64, (6), 653-672.

37. Liu, L.; Li, J.; Yue, F.; Yan, X.; Wang, F.; Bloszies, S.; Wang, Y., Effects of arbuscular mycorrhizal inoculation and biochar amendment on maize growth, cadmium uptake and soil cadmium speciation in Cd-contaminated soil. Chemosphere 2018, 194, 495-503.

38. Wang, S.; Zhang, K.; van Beek, L. P. H.; Tian, X.; Bogaard, T. A., Physically-based landslide prediction over a large region: Scaling low-resolution hydrological model results for high-resolution slope stability assessment. Environmental Modelling \& Software 2020, 124, 104607.

39. Zhang, S.; Zhang, J.; Ma, Y.; Pak, R. Y. S., Vertical dynamic interactions of poroelastic soils and embedded piles considering the effects of pile-soil radial deformations. Soils and Foundations 2020. 
40. Chen, Y.; He, L.; Guan, Y.; Lu, H.; Li, J., Life cycle assessment of greenhouse gas emissions and water-energy optimization for shale gas supply chain planning based on multi-level approach: Case study in Barnett, Marcellus, Fayetteville, and Haynesville shales. Energy Conversion and Management 2017, 134, $382-398$.

41. He, L.; Shen, J.; Zhang, Y., Ecological vulnerability assessment for ecological conservation and environmental management. Journal of Environmental Management 2018, 206, 1115-1125.

42. Singh, V.; Gu, N.; Wang, X., A theoretical framework of a BIM-based multi-disciplinary collaboration platform. Automation in Construction 2011, 20, (2), 134-144.

43. Zhu, J.; Wang, X.; Wang, P.; Wu, Z.; Kim, M. J., Integration of BIM and GIS: Geometry from IFC to shapefile using open-source technology. Automation in Construction 2019, 102, 105-119.

44. Zhu, J.; Wu, P.; Chen, M.; Kim, M. J.; Wang, X.; Fang, T., Automatically Processing IFC Clipping Representation for BIM and GIS Integration at the Process Level. Applied Sciences 2020, 10, (6).

45. Alam, Z.; Zhang, C.; Samali, B., Influence of seismic incident angle on response uncertainty and structural performance of tall asymmetric structure. The Structural Design of Tall and Special Buildings 2020, 29, (12), e1750.

46. Gholipour, G.; Zhang, C.; Mousavi, A. A., Numerical analysis of axially loaded RC columns subjected to the combination of impact and blast loads. Engineering Structures 2020, $219,110924$.

47. Ju, Y.; Shen, T.; Wang, D., Bonding behavior between reactive powder concrete and normal strength concrete. Construction and Building Materials 2020, 242, 118024.

48. Sun, Y.; Wang, J.; Wu, J.; Shi, W.; Ji, D.; Wang, X.; Zhao, X., Constraints hindering the development of highrise modular buildings. Applied Sciences 2020, 10, (20), 7159.

49. Tsai, Y.-H.; Wang, J.; Chien, W.-T.; Wei, C.-Y.; Wang, X.; Hsieh, S.-H., A BIM-based approach for predicting corrosion under insulation. Automation in Construction 2019, 107, 102923.

50. Wang, J.; Huang, Y.; Wang, T.; Zhang, C.; Liu, Y. h., Fuzzy finite-time stable compensation control for a building structural vibration system with actuator failures. Applied Soft Computing 2020, 93, 106372.

51. Zhang, C.; Gholipour, G.; Mousavi, A. A., State-of-the-Art Review on Responses of RC Structures Subjected to Lateral Impact Loads. Archives of Computational Methods in Engineering 2020.

52. Qian, J.; Feng, S.; Li, Y.; Tao, T.; Han, J.; Chen, Q.; Zuo, C., Single-shot absolute 3D shape measurement with deep-learning-based color fringe projection profilometry. Optics Letters 2020, 45, (7), 1842-1845.

53. Qu, S.; Han, Y.; Wu, Z.; Raza, H., Consensus Modeling with Asymmetric Cost Based on Data-Driven Robust Optimization. Group Decision and Negotiation 2020.

54. Yan, J.; Pu, W.; Zhou, S.; Liu, H.; Greco, M. S., Optimal Resource Allocation for Asynchronous Multiple Targets Tracking in Heterogeneous Radar Networks. IEEE Transactions on Signal Processing 2020, 68, 40554068.

55. Yang, W.; Pudasainee, D.; Gupta, R.; Li, W.; Wang, B.; Sun, L., An overview of inorganic particulate matter emission from coal/biomass/MSW combustion: Sampling and measurement, formation, distribution, inorganic composition and influencing factors. Fuel Processing Technology 2020, 106657.

56. Zhang, C.; Alam, Z.; Sun, L.; Su, Z.; Samali, B., Fibre Bragg grating sensor-based damage response monitoring of an asymmetric reinforced concrete shear wall structure subjected to progressive seismic loads. Structural Control and Health Monitoring 2019, 26, (3), e2307.

57. Abedini, M.; Mutalib, A. A.; Zhang, C.; Mehrmashhadi, J.; Raman, S. N.; Alipour, R.; Momeni, T.; Mussa, M. H., Large deflection behavior effect in reinforced concrete columns exposed to extreme dynamic loads. Frontiers of Structural and Civil Engineering 2020, 14, (2), 532-553.

58. Abedini, M.; Zhang, C.; Mehrmashhadi, J.; Akhlaghi, E., Comparison of ALE, LBE and pressure time history methods to evaluate extreme loading effects in RC column. Structures 2020, 28, 456-466.

59. Gholipour, G.; Zhang, C.; Mousavi, A. A., Nonlinear numerical analysis and progressive damage assessment of a cable-stayed bridge pier subjected to ship collision. Marine Structures 2020, 69, 102662.

60. Mou, B.; Zhao, F.; Qiao, Q.; Wang, L.; Li, H.; He, B.; Hao, Z., Flexural behavior of beam to column joints with or without an overlying concrete slab. Engineering Structures 2019, 199, 109616.

61. Sun, L.; Yang, Z.; Jin, Q.; Yan, W., Effect of Axial Compression Ratio on Seismic Behavior of GFRP Reinforced Concrete Columns. International Journal of Structural Stability and Dynamics 2020, 20, (06), 2040004.

62. Zhang, C.; Gholipour, G.; Mousavi, A. A., Nonlinear dynamic behavior of simply-supported RC beams subjected to combined impact-blast loading. Engineering Structures 2019, 181, 124-142.

63. Zhang, C.; Gholipour, G.; Mousavi, A. A., Blast loads induced responses of RC structural members: State-ofthe-art review. Composites Part B: Engineering 2020, 195, 108066.

64. Liu, Y.; Yang, C.; Sun, Q., Thresholds Based Image Extraction Schemes in Big Data Environment in Intelligent Traffic Management. IEEE Transactions on Intelligent Transportation Systems 2020, 1-9.

65. Wang, B.; Zhang, B. F.; Liu, X. W.; Zou, F. C., Novel infrared image enhancement optimization algorithm combined with DFOCS. Optik 2020, 224, 165476.

66. Xu, M.; Li, C.; Zhang, S.; Callet, P. L., State-of-the-Art in $360^{\circ}$ Video/Image Processing: Perception, Assessment and Compression. IEEE Journal of Selected Topics in Signal Processing 2020, 14, (1), 5-26.

67. Yang, M.; Sowmya, A., An Underwater Color Image Quality Evaluation Metric. IEEE Transactions on Image Processing 2015, 24, (12), 6062-6071. 
68. Zenggang, X.; Zhiwen, T.; Xiaowen, C.; Xue-min, Z.; Kaibin, Z.; Conghuan, Y., Research on Image Retrieval Algorithm Based on Combination of Color and Shape Features. Journal of Signal Processing Systems 2019, 18 .

69. Zhu, Q., Research on Road Traffic Situation Awareness System Based on Image Big Data. IEEE Intelligent Systems 2020, 35, (1), 18-26.

70. Salari, N.; Shohaimi, S.; Najafi, F.; Nallappan, M.; Karishnarajah, I., Application of pattern recognition tools for classifying acute coronary syndrome: an integrated medical modeling. Theoretical Biology and Medical Modelling 2013, 10, (1), 57.

71. Xu, S.; Wang, J.; Shou, W.; Ngo, T.; Sadick, A.-M.; Wang, X., Computer Vision Techniques in Construction: A Critical Review. Archives of Computational Methods in Engineering 2020.

72. Li, C.; Sun, L.; Xu, Z.; Wu, X.; Liang, T.; Shi, W., Experimental Investigation and Error Analysis of High Precision FBG Displacement Sensor for Structural Health Monitoring. International Journal of Structural Stability and Dynamics 2020, 2040011.

73. Abedini, M.; Zhang, C., Dynamic performance of concrete columns retrofitted with FRP using segment pressure technique. Composite Structures 2021, 260, 113473.

74. Kordestani, H.; Zhang, C., Direct Use of the Savitzky-Golay Filter to Develop an Output-Only Trend LineBased Damage Detection Method. Sensors 2020, 20, (7), 1983.

75. Kordestani, H.; Zhang, C.; Shadabfar, M., Beam Damage Detection Under a Moving Load Using Random Decrement Technique and Savitzky-Golay Filter. Sensors 2020, 20, (1), 243.

76. Zhang, C.; Abedini, M.; Mehrmashhadi, J., Development of pressure-impulse models and residual capacity assessment of RC columns using high fidelity Arbitrary Lagrangian-Eulerian simulation. Engineering Structures 2020, 224, 111219.

77. Zhang, C.; Wang, H., Swing vibration control of suspended structures using the Active Rotary Inertia Driver system: Theoretical modeling and experimental verification. Structural Control and Health Monitoring 2020, $27,(6)$, e 2543.

78. Alam, Z.; Sun, L.; Zhang, C.; Su, Z.; Samali, B., Experimental and numerical investigation on the complex behaviour of the localised seismic response in a multi-storey plan-asymmetric structure. Structure and Infrastructure Engineering 2020, 1-17.

79. Alam, Z.; Zhang, C.; Samali, B., The role of viscoelastic damping on retrofitting seismic performance of asymmetric reinforced concrete structures. Earthquake Engineering and Engineering Vibration 2020, 19, (1), 223-237.

80. He, L.; Chen, Y.; Li, J., A three-level framework for balancing the tradeoffs among the energy, water, and airemission implications within the life-cycle shale gas supply chains. Resources, Conservation and Recycling 2018, 133, 206-228.

81. Wang, Y.; Yao, M.; Ma, R.; Yuan, Q.; Yang, D.; Cui, B.; Ma, C.; Liu, M.; Hu, D., Design strategy of barium titanate/polyvinylidene fluoride-based nanocomposite films for high energy storage. Journal of Materials Chemistry A 2020, 8, (3), 884-917.

82. Yang, C.; Gao, F.; Dong, M., Energy Efficiency Modeling of Integrated Energy System in Coastal Areas. Journal of Coastal Research 2020, 103, (SI), 995-1001.

83. Zhang, W., Parameter Adjustment Strategy and Experimental Development of Hydraulic System for Wave Energy Power Generation. Symmetry 2020, 12, (5), 711.

84. Zhao, X.; Ye, Y.; Ma, J.; Shi, P.; Chen, H., Construction of electric vehicle driving cycle for studying electric vehicle energy consumption and equivalent emissions. Environmental Science and Pollution Research 2020, 115.

85. Zhu, L.; Kong, L.; Zhang, C., Numerical Study on Hysteretic Behaviour of Horizontal-Connection and EnergyDissipation Structures Developed for Prefabricated Shear Walls. Applied Sciences 2020, 10, (4), 1240.

86. Zuo, X.; Dong, M.; Gao, F.; Tian, S., The modeling of the electric heating and cooling system of the integrated energy system in the coastal area. Journal of Coastal Research 2020, 103, (SI), 1022-1029.

87. Chen, Y.; He, L.; Li, J.; Zhang, S., Multi-criteria design of shale-gas-water supply chains and production systems towards optimal life cycle economics and greenhouse gas emissions under uncertainty. Computers \& Chemical Engineering 2018, 109, 216-235.

88. Deng, Y.; Zhang, T.; Sharma, B. K.; Nie, H., Optimization and mechanism studies on cell disruption and phosphorus recovery from microalgae with magnesium modified hydrochar in assisted hydrothermal system. Science of The Total Environment 2019, 646, 1140-1154.

89. Feng, S.; Lu, H.; Tian, P.; Xue, Y.; Lu, J.; Tang, M.; Feng, W., Analysis of microplastics in a remote region of the Tibetan Plateau: Implications for natural environmental response to human activities. Science of The Total Environment 2020, 739, 140087.

90. Fu, X.; Fortino, G.; Pace, P.; Aloi, G.; Li, W., Environment-fusion multipath routing protocol for wireless sensor networks. Information Fusion 2020, 53, 4-19.

91. Han, X.; Zhang, D.; Yan, J.; Zhao, S.; Liu, J., Process development of flue gas desulphurization wastewater treatment in coal-fired power plants towards zero liquid discharge: Energetic, economic and environmental analyses. Journal of Cleaner Production 2020, 261, 121144. 
92. Hu, J.; Zheng, B.; Wang, C.; Zhao, C.; Hou, X.; Pan, Q.; Xu, Z., A survey on multi-sensor fusion based obstacle detection for intelligent ground vehicles in off-road environments. Frontiers Inf. Technol. Electron. Eng. 2020, $21,(5), 675-692$.

93. Liu, J.; Liu, Y.; Wang, X., An environmental assessment model of construction and demolition waste based on system dynamics: a case study in Guangzhou. Environmental Science and Pollution Research 2020, 27, (30), 37237-37259.

94. Zhang, T.; He, X.; Deng, Y.; Tsang, D. C. W.; Yuan, H.; Shen, J.; Zhang, S., Swine manure valorization for phosphorus and nitrogen recovery by catalytic-thermal hydrolysis and struvite crystallization. Science of The Total Environment 2020, 729, 138999

95. Cao, B.; Dong, W.; Lv, Z.; Gu, Y.; Singh, S.; Kumar, P., Hybrid Microgrid Many-Objective Sizing Optimization With Fuzzy Decision. IEEE Transactions on Fuzzy Systems 2020, 28, (11), 2702-2710.

96. Cao, B.; Zhao, J.; Gu, Y.; Ling, Y.; Ma, X., Applying graph-based differential grouping for multiobjective largescale optimization. Swarm and Evolutionary Computation 2020, 53, 100626.

97. Liu, S.; Chan, F. T. S.; Ran, W., Decision making for the selection of cloud vendor: An improved approach under group decision-making with integrated weights and objective/subjective attributes. Expert Systems with Applications 2016, 55, 37-47.

98. Wu, C.; Wu, P.; Wang, J.; Jiang, R.; Chen, M.; Wang, X., Critical review of data-driven decision-making in bridge operation and maintenance. Structure and Infrastructure Engineering 2020, 1-24.

99. Cao, B.; Zhao, J.; Lv, Z.; Gu, Y.; Yang, P.; Halgamuge, S. K., Multiobjective Evolution of Fuzzy Rough Neural Network via Distributed Parallelism for Stock Prediction. IEEE Transactions on Fuzzy Systems 2020, 28, (5), 939-952.

100. Shi, K.; Wang, J.; Tang, Y.; Zhong, S., Reliable asynchronous sampled-data filtering of T-S fuzzy uncertain delayed neural networks with stochastic switched topologies. Fuzzy Sets and Systems 2020, 381, 1-25.

101. Shi, K.; Wang, J.; Zhong, S.; Tang, Y.; Cheng, J., Non-fragile memory filtering of T-S fuzzy delayed neural networks based on switched fuzzy sampled-data control. Fuzzy Sets and Systems 2020, 394, 40-64.

102. Wang, J.; Zhu, P.; He, B.; Deng, G.; Zhang, C.; Huang, X., An Adaptive Neural Sliding Mode Control with ESO for Uncertain Nonlinear Systems. International Journal of Control, Automation and Systems 2020.

103. Yang, L.; Chen, H., Fault diagnosis of gearbox based on RBF-PF and particle swarm optimization wavelet neural network. Neural Computing and Applications 2019, 31, (9), 4463-4478.

104. Yang, S.; Deng, B.; Wang, J.; Li, H.; Lu, M.; Che, Y.; Wei, X.; Loparo, K. A., Scalable Digital Neuromorphic Architecture for Large-Scale Biophysically Meaningful Neural Network With Multi-Compartment Neurons. IEEE Transactions on Neural Networks and Learning Systems 2020, 31, (1), 148-162.

105. Zhang, X.; Wang, Y.; Chen, X.; Su, C.; Li, Z.; Wang, C.; Peng, Y., Decentralized Adaptive Neural Approximated Inverse Control for a Class of Large-Scale Nonlinear Hysteretic Systems With Time Delays. IEEE Transactions on Systems, Man, and Cybernetics: Systems 2019, 49, (12), 2424-2437.

106. Sonmez, Y.; Guvenc, U.; Kahraman, H. T.; Yilmaz, C. In A comperative study on novel machine learning algorithms for estimation of energy performance of residential buildings, 2015 3rd International Istanbul Smart Grid Congress and Fair (ICSG), 2015; IEEE: pp 1-7.

107. Hassoun, M. H., Fundamentals of artificial neural networks. MIT press: 1995.

108. Steinwart, I.; Christmann, A., Support vector machines. Springer Science \& Business Media: 2008.

109. Jang, J.-S., ANFIS: adaptive-network-based fuzzy inference system. IEEE transactions on systems, man, and cybernetics 1993, 23, (3), 665-685.

110. Namlı, E.; Erdal, H.; Erdal, H. I., Artificial Intelligence-Based Prediction Models for Energy Performance of Residential Buildings. In Recycling and Reuse Approaches for Better Sustainability, Springer: 2019; pp 141149.

111. Galante, A.; Torri, M., A methodology for the energy performance classification of residential building stock on an urban scale. Energy and Buildings 2012, 48, 211-219.

112. Pezeshki, Z.; Mazinani, S. M., Comparison of artificial neural networks, fuzzy logic and neuro fuzzy for predicting optimization of building thermal consumption: a survey. Artificial Intelligence Review 2019, 52, (1), 495-525.

113. Deb, C.; Eang, L. S.; Yang, J.; Santamouris, M., Forecasting diurnal cooling energy load for institutional buildings using Artificial Neural Networks. Energy and Buildings 2016, 121, 284-297.

114. Martin, G. L.; Monfet, D.; Nouanegue, H. F.; Lavigne, K.; Sansregret, S., Energy calibration of HVAC subsystem model using sensitivity analysis and meta-heuristic optimization. Energy and Buildings 2019, 202, 109382.

115. Bamdad Masouleh, K. Building energy optimisation using machine learning and metaheuristic algorithms. Queensland University of Technology, 2018.

116. Ghahramani, A.; Karvigh, S. A.; Becerik-Gerber, B., HVAC system energy optimization using an adaptive hybrid metaheuristic. Energy and Buildings 2017, 152, 149-161.

117. Fong, K. F.; Hanby, V. I.; Chow, T.-T., HVAC system optimization for energy management by evolutionary programming. Energy and Buildings 2006, 38, (3), 220-231.

118. Jitkongchuen, D.; Pacharawongsakda, E. In Prediction Heating and Cooling Loads of Building Using Evolutionary Grey Wolf Algorithms, 2019 Joint International Conference on Digital Arts, Media and Technology 
with ECTI Northern Section Conference on Electrical, Electronics, Computer and Telecommunications Engineering (ECTI DAMT-NCON), IEEE: pp 93-97.

119. Saini, B.; Sehgal, V.; Gambhir, M., Least-cost design of singly and doubly reinforced concrete beam using genetic algorithm optimized artificial neural network based on Levenberg-Marquardt and quasi-Newton backpropagation learning techniques. Structural and Multidisciplinary Optimization 2007, 34, (3), 243-260.

120. Chen, W.; Panahi, M.; Pourghasemi, H. R., Performance evaluation of GIS-based new ensemble data mining techniques of adaptive neuro-fuzzy inference system (ANFIS) with genetic algorithm (GA), differential evolution (DE), and particle swarm optimization (PSO) for landslide spatial modelling. Catena 2017, 157, 310 324.

121. Moayedi, H.; Nguyen, H.; Foong, L., Nonlinear evolutionary swarm intelligence of grasshopper optimization algorithm and gray wolf optimization for weight adjustment of neural network. Engineering with Computers. 2019.

122. Le, L. T.; Nguyen, H.; Dou, J.; Zhou, J., A Comparative Study of PSO-ANN, GA-ANN, ICA-ANN, and ABCANN in Estimating the Heating Load of Buildings' Energy Efficiency for Smart City Planning. Applied Sciences 2019, 9, (13), 2630.

123. Tien Bui, D.; Moayedi, H.; Anastasios, D.; Kok Foong, L., Predicting heating and cooling loads in energyefficient buildings using two hybrid intelligent models. Applied Sciences 2019, 9, (17), 3543.

124. Moayedi, H.; Mu'azu, M. A.; Foong, L. K., Novel Swarm-based Approach for Predicting the Cooling Load of Residential Buildings Based on Social Behavior of Elephant Herds. Energy and Buildings 2019, 109579.

125. Zhou, G.; Moayedi, H.; Bahiraei, M.; Lyu, Z., Employing artificial bee colony and particle swarm techniques for optimizing a neural network in prediction of heating and cooling loads of residential buildings. Journal of Cleaner Production 2020.

126. Simon, D., Biogeography-based optimization. IEEE transactions on evolutionary computation 2008, 12, (6), 702-713.

127. Moayedi, H.; Osouli, A.; Bui, D. T.; Kok Foong, L.; Nguyen, H.; Kalantar, B., Two novel neural-evolutionary predictive techniques of dragonfly algorithm (DA) and biogeography-based optimization (BBO) for landslide susceptibility analysis. Geomatics, Natural Hazards and Risk 2019, 10, (1), 2429-2453.

128. Mehrabian, A. R.; Lucas, C., A novel numerical optimization algorithm inspired from weed colonization. Ecological informatics 2006, 1, (4), 355-366.

129. James, J.; Li, V. O., A social spider algorithm for global optimization. Applied Soft Computing 2015, 30, 614627.

130. Eusuff, M. M.; Lansey, K. E., Optimization of water distribution network design using the shuffled frog leaping algorithm. Journal of Water Resources planning and management 2003, 129, (3), 210-225.

131. Geem, Z. W.; Kim, J. H.; Loganathan, G. V., A new heuristic optimization algorithm: harmony search. simulation 2001, 76, (2), 60-68.

132. Lee, A.; Geem, Z. W.; Suh, K.-D., Determination of optimal initial weights of an artificial neural network by using the harmony search algorithm: application to breakwater armor stones. Applied Sciences 2016, 6, (6), 164.

133. KAZEMI, E. N.; Shabakhty, N.; ABBASI, K. M.; SANAYEE, M. S., Structural reliability: an assessment using a new and efficient two-phase method based on artificial neural network and a harmony search algorithm. 2016.

134. Mirjalili, S.; Mirjalili, S. M.; Lewis, A., Let a biogeography-based optimizer train your multi-layer perceptron. Information Sciences 2014, 269, 188-209.

135. Zhao, F.; Du, S.; Zhang, Y.; Ma, W.; Song, H., Hybrid biogeography-based optimization with enhanced mutation and CMA-ES for global optimization problem. Service Oriented Computing and Applications 2020, 1-9.

136. Moayedi, H.; Tien Bui, D.; Dounis, A.; Kok Foong, L.; Kalantar, B., Novel Nature-Inspired Hybrids of Neural Computing for Estimating Soil Shear Strength. Applied Sciences 2019, 9, (21), 4643.

137. Nagaraju, T. V.; Prasad, C. D.; Murthy, N., Invasive Weed Optimization Algorithm for Prediction of Compression Index of Lime-Treated Expansive Clays. In Soft Computing for Problem Solving, Springer: 2020; pp 317-324.

138. Kumar, D.; Gandhi, B. R.; Bhattacharjya, R. K., Introduction to Invasive Weed Optimization Method. In NatureInspired Methods for Metaheuristics Optimization, Springer: 2020; pp 203-214.

139. James, J.; Li, V. O., A social spider algorithm for solving the non-convex economic load dispatch problem. Neurocomputing 2016, 171, 955-965.

140. Siahbalaee, J.; Rezanejad, N.; Gharehpetian, G. B., Reconfiguration and DG Sizing and Placement Using Improved Shuffled Frog Leaping Algorithm. Electric Power Components and Systems 2020, 1-14.

141. Gandhi, B. R.; Bhattacharjya, R., Introduction to Shuffled Frog Leaping Algorithm and Its Sensitivity to the Parameters of the Algorithm. In Nature-Inspired Methods for Metaheuristics Optimization, Springer: 2020; pp 105-117.

142. Chen, K.; Mao, Z.; Zhao, H.; Jiang, Z.; Zhang, J., A Variational Stacked Autoencoder with Harmony Search Optimizer for Valve Train Fault Diagnosis of Diesel Engine. Sensors 2020, 20, (1), 223.

143. Zhu, Q.; Tang, X.; Li, Y.; Yeboah, M. O., An improved differential-based harmony search algorithm with linear dynamic domain. Knowledge-Based Systems 2020, 187, 104809. 
144. Sirjani, R.; Mohamed, A.; Shareef, H., Optimal allocation of shunt Var compensators in power systems using a novel global harmony search algorithm. International Journal of Electrical Power \& Energy Systems 2012, 43, (1), 562-572.

145. Tsanas, A.; Xifara, A., Accurate quantitative estimation of energy performance of residential buildings using statistical machine learning tools. Energy and Buildings 2012, 49, 560-567.

146. Roberts, A.; Marsh, A., ECOTECT: environmental prediction in architectural education. 2001. 